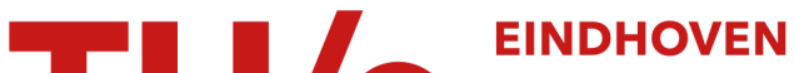 UNIVERSITY OF TECHNOLOGY
}

\section{Determination of sulfur components in natural gas: a review}

\section{Citation for published version (APA):}

Pham Tuan, H., Janssen, J. G. M., Cramers, C. A., Smit, A. L. C., \& Kuiper-Van Loo, E. M. (1994).

Determination of sulfur components in natural gas: a review. Journal of High Resolution Chromatography, 17(6), 373-389. https://doi.org/10.1002/jhrc.1240170603

DOI:

10.1002/jhrc. 1240170603

Document status and date:

Published: 01/01/1994

\section{Document Version:}

Publisher's PDF, also known as Version of Record (includes final page, issue and volume numbers)

\section{Please check the document version of this publication:}

- A submitted manuscript is the version of the article upon submission and before peer-review. There can be important differences between the submitted version and the official published version of record. People interested in the research are advised to contact the author for the final version of the publication, or visit the $\mathrm{DOI}$ to the publisher's website.

- The final author version and the galley proof are versions of the publication after peer review.

- The final published version features the final layout of the paper including the volume, issue and page numbers.

Link to publication

\section{General rights}

Copyright and moral rights for the publications made accessible in the public portal are retained by the authors and/or other copyright owners and it is a condition of accessing publications that users recognise and abide by the legal requirements associated with these rights.

- Users may download and print one copy of any publication from the public portal for the purpose of private study or research.

- You may not further distribute the material or use it for any profit-making activity or commercial gain

- You may freely distribute the URL identifying the publication in the public portal.

If the publication is distributed under the terms of Article 25fa of the Dutch Copyright Act, indicated by the "Taverne" license above, please follow below link for the End User Agreement:

www.tue.nl/taverne

Take down policy

If you believe that this document breaches copyright please contact us at:

openaccess@tue.nl

providing details and we will investigate your claim. 


\title{
Determination of Sulfur Components in Natural Gas: A Review
}

\author{
Hai Pham Tuan, Hans-Gerd Janssen`, and Carel A. Cramers, \\ Eindhoven University of Technology, Laboratory for Instrumental Analysis, P.O. Box 513, 5600 MB Eindhoven, The Netherlands
}

André L. C. Smit and Ellen M. van Loo,

N.V. Nederlandse Gasunie, P.O. Box 19, 9700 MA Groningen, The Netherlands

\section{Key Words: \\ GC \\ Natural gas analysis \\ Sulfur components \\ Selective enrighment \\ Sulfur selective detection \\ Calibration}

\begin{abstract}
Summary
More stringent environmental regulations as well as higher demands presently being imposed on the sulfur content of natural gas feed-stocks for chemical processes necessitate the development of new analytical procedures for sulfur determination in natural gas. Only analytical procedures based on gas chromatography can meet the sensitivity and accuracy requirements dictated by environmental regulation institutions and modern chemical industry. The complexity of the natural gas matrix as well as the extremely low concentration levels at which the sulfur species occur make the development of these analytical methods a true challenge. In this review the three steps common for analytical methods for trace analysis in complex matrices, i.e. pretreatment, chromatographic separation, and detection, are discussed in detail. Possible methods for calibration of the system are discussed in the final section.
\end{abstract}

Various techniques to determine sulfur in natural gas are described. Depending on the application, the most suitable system has to be selected. For example, for on-line application in a hazardous area a simple and rugged system is required, i.e. a simple gas chromatograph with a flame photometric detector, while for laboratory application a more complex instrument including preconcentration, column switching, and more exotic detection systems could be more suitable. Therefore it is crucial to define the requirements of the instrument at an early stage and use the information in this review article to develop/select a dedicated instrument/procedure for the problem at hand.

\section{Introduction}

Natural gas is a well established contributor to the world's energy needs. At this moment the use of natural gas comprises over $20 \%$ of the total energy consumed world-wide. Furthermore, natural gas is also an important starting material in a number of large-scale production processes in the chemical industry. The presence of sulfur components in natural gas constitutes a source of concern because of the corrosive nature of these components as well as their potential hazards for human health and for the natural environment. Additionally, if natural gas is used as a reagent in chemical processes, sulfur species present in the gas may adversely affect the performance and life-time of catalysts involved in the reaction.

For the reasons outlined above, the accurate determination of sulfur components in natural gas is of utmost importance. The group of components that should be analyzed includes hydrogen sulfide, carbonyl sulfide, the $\mathrm{C}_{1}$ to $\mathrm{C}_{4}$ mercaptans, lower sulfides and odorants, such as for example tetrahydrothiophene (THT), added to the gas to impart a characteristic smell for safety purposes. The concentrations of these components differ, depending on the origin of the gas. In general, the concentrations of sulfur components in natural gas for domestic and industrial use range typically from a few to several tens of parts per million on a volume basis. An exception is $\mathrm{H}_{2} \mathrm{~S}$ which can be present at concentration levels up to one percent [1].

Standardized methods for the determination of sulfur species in natural gas have been published by the Intemational Organisation for Standardization (ISO). They can be classified as either conventional techniques (Wickbold, Lingener) or modern instrumental techniques (GC-based). ISO standard 4260 describes the Wickbold combustion method, a method for the determination of the totalsulfur content of natural- and other gases. In the Wickbold method the natural gas sample is supplied to the burner of an oxy-hydrogen flame, where the sulfur compounds are burnt with a considerable excess of oxygen. The resulting sulfur oxides are converted into sulfuric acid by absorption in a hydrogen peroxide solution. Depending on the sulfur content of the sample, the sulfate ions in the absorption solution are determined by colorimetric, nephelometric, turbidimetric or conductometric titrations. More recently, ISO standard 6326-5 was published. This standard procedure describes the use of the Lingener combustion method. In the Lingener method a given volume of natural gas is burnt with air at atmospheric pressure in an enclosed combustion apparatus. The resulting sulfur oxides are oxidized to sulfuric acid by absorption in a hydrogen peroxide solution and afterwards titrated with a barium chloride solution. The total sulfur content which can be determined with this measurement method is $10-1000 \mathrm{mg} \mathrm{S} / \mathrm{m}^{3}$ [2].

As opposed to the Lingener and the Wickbold method, which both measure the total sulfur content, ISO method 6326-3 describes a potentiometric method for sulfur determination that only reponds to hydrogen sulfide, mercaptans and carbonyl sulfide. In this method hydrogen sulfide and mercaptans are absorbed in a $40 \%$ $(\mathrm{m} / \mathrm{m})$ potassium hydroxide solution; carbonyl sulfide is absorbed downstream in a $5 \%(\mathrm{~m} / \mathrm{m})$ alcoholic mono ethanolamine solution and afterwards titration of the absorbed hydrogen sulfide, mercaptans and carbonyl sulfide is performed with a silver nitrate solution. The concentration range of sulfur compounds which can be deter- 
mined with this measurement method is $1-10 \mathrm{mg} \mathrm{S} / \mathrm{m}^{3}$ for $\mathrm{H}_{2} \mathrm{~S}, 1$ $-20 \mathrm{mg} \mathrm{S} / \mathrm{m}^{3}$ for mercaptans and $1-30 \mathrm{mg} \mathrm{S} / \mathrm{m}^{3}$ for COS [2].

Apart from one common advantage, i.e. no calibration procedure is needed as the three methods described above are absolute measurement techniques, they also suffer from a number of common disadvantages. The measurements are time-consuming, complex and are, due to the complexity of the experimental steps involved, difficult to automate. Moreover, the accuracy and the detection limits of especially the Lingener method do not meet the required limits. It is evident that because the methods measure the total sulfur content (ISO 4260 and ISO 6326-5) or the concentration of different classes of sulfur compounds (ISO 6326-3), no information on the concentrations of the individual sulfur species is obtained. This disadvantage can be overcome by using GC-based methods for sulfur determination. The ISO standards 6326-2 and 6326-4 describe gas chromatographic methods for separation and detection of individual sulfur components in natural gas. In ISO 6326-2 hydrogen sulfide, methyl to butyl mercaptans and tetrahydrothiophene (THT) are separated on a gas chromatographic system equipped with a separation column containing $30 \%(\mathrm{~m} / \mathrm{m})$ silicone oil and $30 \%(\mathrm{~m} / \mathrm{m})$ dinonyl phthalate on Chromosorb $\mathrm{W}$. The sulfur compounds are subsequently detected with an electrochemical cell, in which they are oxidized by a chromium oxide solution and at the same time the potential difference over the platinum electrodes is measured. The ISO 6236-2 method suffers from two serious disadvantages. Firstly, it is not applicable for the determination of carbonyl sulfide. Furthermore, the chromatographic conditions specified in the method only enable hydrogen sulfide and methylmercaptan to be determined if the ratio of the concentration of the former to the concentration of the latter is less than 10 . The same applies for the quantification of two thiols eluted consecutively

A few of the major limitations of the ISO 6326-2 method were eliminated in ISO 6326-4. The chromatographic separation of the sulfur components was optimized, resulting in a system that enabled quantification of all major sulfur species in natural gas samples. The components are separated using a temperature programmed $1.2 \mathrm{~m} \times 2 \mathrm{~mm}$ column packed with styrene/divinylbenzene porous polymer beads ( $80-100$ mesh) and measured with a sulfur-selective flame photometric detector (FPD). The detection limit is approximately $0.1 \mathrm{mg} \mathrm{S} / \mathrm{m}^{3}$, which is comparable to the detection limits obtainable by the ISO standard method 6326-2

The ISO methods 6326-2 and 6326-4 yield the concentrations of the individual sulfur components in the gas. The total S concentration can then be obtained by summing the equivalent S-weights of the individual components. The chromatographic separation procedure incorporated in ISO 6326-4 provides sufficient separation of all sulfur components. Unfortunately, however, it still has a number of problems, most of which originate from the use of flame photometric detection. The selectivity of the flame photometric detector (FPD) is limited and, although fairly selective, this detector still responds to high concentrations of non-sulfur components. Moreover, high concentrations of hydrocarbons coeluting with a sulfurcontaining component can quench the sulfur signal. Finally, the response of the FPD is inherently non-linear and often also compound dependent. For these reasons, the concentration of the sulfur species to be determined are limited to the range of $0.1-30 \mathrm{mg} \mathrm{S} / \mathrm{m}^{3}$.

For most present applications, the detection limits and the reliability of the analytical results achievable by GC with FPD detection are within the desired range. More stringent environmental regulations as well as higher demands currently being posed on the purity of natural feed-stocks for chemical processes, however, force analytical chemists to develop new analytical methods that allow the accurate and reliable determination of sulfur in natural gas at concentrations well below the limits currently achievable. The complexity of the natural gas matrix and the extremely low detection limits required render this task extremely challenging. Analytical methods for analyses at trace levels in complex and interfering matrices often require the use of selective preconcentration/enrichment techniques. Only if this step and the subsequent separation and detection are fully optimized, it is possible to meet the required sensitivity limits with an acceptable level of reliability. In the vast majority of applications, the demands posed on each of these three steps is determined by the performance of the other two. If, for example, a universal detector is employed, the requirements imposed on the sample pretreatment and separation are much more stringent than in the case of the use of a truely specific detector

In subsequent chapters of this review each of the three steps of the analytical procedure for the quantification of low concentrations of sulpur components in natural gas, i.e. sample pretreatment, separation and detection, will be discussed in detail. Up till now, virtually no attention has been paid in literature to the use of preconcentration techniques in natural gas analysis. On the other hand, various methods for preconcentration of sulfur in samples of environmental or medical origin have been published. In general, the principles of these methods are also applicable for trace analysis of sulfur in natural gas. Irrespective of the matrix, the strong tendency of sulfur components to adsorb on various types of surfaces seriously complicates preconcentration and analysis of these compounds. In literature, both packed and open-tubular columns have been employed for the separation of sulfur species in a wide variety of samples. In a chapter devoted to the chromatographic separation of sulfur components, the merits of each of these two approaches will be compared. The selection of the detection device is of crucial importance for the performance of the combined set-up. Various detectors will be considered in a separate chapter. As opposed to the three standardized absolute methods for sulfur determination described earlier, GC-based techniques are relative methods and hence require calibration. Procedures for calibration will be treated in detail in the last chapter. Again, the adsorptive nature of sulfur components constitutes a serious source of concern in preparation and storage of sulfur calibration mixtures.

\section{Trace Enrichment of Sulfur Components}

The determination of trace components in a complex matrix often requires selective enrichment of the components of interest prior to transfer of the sample into the chromatographic system. In this step the target compounds are selectively retained on for example a solid adsorbent or a cold trap while at the same time the interfering main components are eliminated For the particular case of sulfur determination in natural gas this means a material is required that selectively adsorbs sulfur containing species without adsorbing hydrocarbons.

Up till now, no preconcentration techniques have been developed for the GC determination of sulfur components in natural gas. Several preconcentration methods, however, were described for determination of these compounds in ambient air. Due to the low concentrations of sulfur components in air a preconcentration step prior to analysis is virtually always required.

Early work in this field, without connection to a GC separation $[3,4]$, often reports collection methods for individual sulfur compounds from an atmospheric matrix by wet chemical techniques or by using impregnated filters with subsequent spectrophotometric analysis. West and Gaeke [5] developed a nowadays traditional wet chemical 
technique for atmospheric sulfur dioxide $\left(\mathrm{SO}_{2}\right)$ measurements. This method uses a bubbler trapping system containing a tetrachloromercurate (II) $\left(\mathrm{HgCl}_{2}+2 \mathrm{NaCl}\right)$ solution. The analysis is spectrophotometric, involving the dye pararosaniline. The West-Gaeke procedure has been successfully used to measure concentrations as low as $5 \mathrm{ppb}^{1}{ }^{1}$. Axelrod et al. [4] used an alternative to the bubbler sampling method, i.e. the use of an impregnated filter containing the same solution, and were able to determine $\mathrm{SO}_{2}$ in concentrations down to $0.05 \mathrm{ppb}$. Similarly, $\mathrm{H}_{2} \mathrm{~S}$ [3] was extracted from air by reaction with an $\mathrm{AgNO}_{3}$ impregnated filter. The resulting $\mathrm{Ag}_{2} \mathrm{~S}$ was dissolved in a NaCN solution and analyzed fluormetrically by using a very dilute fluorescein mercuric acetate. A detection limit of $5 \mathrm{ppt}$ was reported. In both experiments very high collection efficiencies were achieved: $92-95 \%$.

For determination of $\mathrm{H}_{2} \mathrm{~S}$ and other organosulfur compounds in air Braman et al. [6] used preconcentration of the components in a trap filled with gold coated glass beads. Sulfur compounds and $\mathrm{H}_{2} \mathrm{~S}$ were removed by heating the trap $\left(500-600{ }^{\circ} \mathrm{C}\right.$ for $\left.5 \mathrm{~min}\right)$ and were subsequently separated on a short liquid nitrogen cooled U-trap column, and detected by means of a flame photometric detector (FPD). These authors reported detection limits of approximately 0.01 $\mathrm{ng}$ or $0.1 \mathrm{ppt}$ for $100 \mathrm{~L}$ sample. Collection efficiencies of several metal-foils for a larger group of atmospheric sulfur gases were examined by Kagel and Farwell [7]. Here the compounds were released by flash desorption and determined by an FPD. These authors found Pd and Pt foils to be the best for the preconcentration of the gases of interest. The collection efficiencies ranged from $13 \%$ for $\mathrm{COS}$ on Pt-foil to $45 \%$ for $\mathrm{H}_{2} \mathrm{~S}$ on Pd-foil. The sulfur gas detectability of this metal foil collection / flash vaporization / flame photometric detection (MC/FV/FPD) approach was less than $50 \mathrm{ppt}$. A similar method of desorption and detection (FV/FPD) was employed by Farwell et al. [8]. $\mathrm{SO}_{2}$ was collected in a glass fibre filter after complete thermal conversion of the reduced sulfur gases to $\mathrm{SO}_{2}$ in a quartz tube held at a furnace temperature of $1050^{\circ} \mathrm{C}$. The recoveries here were $100 \%$. No detection limits were reported. Also no information on the applicability of this approach for the isolation of other sulfur species is available.

The largest group of collection materials used for preconcentrating sulfur components are the solid adsorbents, which were used both at ambient as well as at subambient temperature (cryogenic trapping). An attractive aspect of the use of solid adsorbents is their capability to be directly coupled to a GC system. An effective solid adsorbent should fulfill the following criteria: (i) high breakthrough volume ${ }^{2)}$. This means a high capacity for the compounds of interest but as low as possible for other interfering components; (ii) easy to desorb.

Black et al. [9] tried to collect $\mathrm{SO}_{2}$ and $\mathrm{H}_{2} \mathrm{~S}$ in glass tubes packed with several non-polar adsorbents such as Tenax GC, Carbopak B, Porapak Q or P, Chromosorb 102, Mol. Sieve 5 A and Mol. Sieve 13X. They found Molecular Sieve 5A to be the best solid adsorbent for these sulfur gases at ambient temperature $\left(25^{\circ} \mathrm{C}\right)$. All tubes were conditioned prior to use by heating at a high temperature (200 $250^{\circ} \mathrm{C}$ for $10-12$ hours) under nitrogen. This conditioning step was required for obtaining quantitative recoveries and sharp desorption profiles. The selected Molecular Sieve material showed the highest

\footnotetext{
${ }^{13}$ For gaseous samples the unit ppm is defined as $10^{-6} \mathrm{~mol} / \mathrm{mol}$, this in contrast to the situation in liquids where one ppm is usually defined as one $\mathrm{mg} / \mathrm{L}$. This can lead to confusion as some authors incorrectly apply the liquid definition of ppm to gases.

${ }^{2)}$ Breakthrough volume, defined as the volume of gas that can be passed through an adsorbent before the investigated compound begins to be eluted.
}

breakthrough volume (ca. $25 \mathrm{~L} / \mathrm{g})$ and released the adsorbed components almost completely during the thermal desorption process $\left(1\right.$ minute at $\left.258{ }^{\circ} \mathrm{C}\right)$. The recoveries were $83-87 \%$ for $\mathrm{SO}_{2}$ and $75-$ $82 \%$ for $\mathrm{H}_{2} \mathrm{~S}$. The GC analysis was carried out on a Teflon column packed with Supelpak S. Detection using an FPD yielded detection limits in the ppb range for both gases. For the specific purpose of sulfur determination in natural gas the applicability of the non-polar adsorbents such as those studied by Black et al. appears to be limited as these materials are most likely not capable of selectively isolating sulfur species from a large excess of hydrocarbons.

For the simultaneous collection of a larger group of sulfur compounds in air (COS, $\mathrm{H}_{2} \mathrm{~S}$, methyl mercaptan (MeSH), $\mathrm{CS}_{2}$, dimethyl sulfide (DMS) and dimethyl disulfide (DMDS)) Steudler et al. [10] used a combination of two solid adsorbents: Molecular Sieve $5 \mathrm{~A}$ for $\mathrm{SO}_{2}$ and $\mathrm{H}_{2} \mathrm{~S}$ and Tenax $\mathrm{GC}$ for the others. The specially designed adsorption tubes showed a very high affinity for the sulfur compounds tested and yielded acceptable recoveries, varying from $50 \%$ for DMDS to $75 \%$ for COS. The recovery efficiencies were found to be a function of the desorption temperature, time and the helium gas flow rate during desorption. Because of the long time required for thermal desorption, it was necessary to cryogenically focus the desorbed sulfur gases in a Teflon loop cooled by liquid nitrogen before injection onto the GC column. The detection limits achieved were $8.8-20 \mathrm{pg}$ of $\mathrm{S}$ depending on the various sulfur gases (FPD). An interesting observation was that the recoveries appeared to be constant for each sulfur gas within the humidity range studied ( 30 $-95 \%)$. Again the application of a very strong non-selective adsorbent such as Mol. Sieve 5A precludes the use of this set-up for selective enrichment of sulfur components from natural gas.

In contrast to the results published by Steudler, Przyjazny [11] in his comparative study of several porous polymers (Chromosorb 102, XAD-2, XAD-4, XAD-7, Tenax GC) concluded that Tenax GC is a poor adsorbent for organosulfur compounds (thiols, sulfides, disulfides, thiophenes). XAD-4, with its extremely large specific surface area $\left(850 \mathrm{~m}^{2} / \mathrm{g}\right)$ was found to have the highest sorption capacity. Unfortunately, the long time necessary for complete thermal desorption makes the following GC analysis more difficult unless a cryogenic focusing step is employed. For samples consisting of high-boiling components only, Tenax GC may be the adsorbent of choice, because of its high thermal stability and relatively low desorption volumes. These characteristics would allow the sample components to be desorbed more rapidly from Tenax than from other sorbents. Also the sorption of MeSH and DMS on the carbon molecular sieve Carbosphere was investigated. The breakthrough volumes determined were ca. $2900 \mathrm{~L} / \mathrm{g}$ for both sulfur compounds. Hence, this sorbent can be used for preconcentration of MeSH and DMS from samples containing extremely low levels of these contaminants. However, thermal desorption from Carbosphere is very difficult due to strong retention of the different sulfur denivates.

Tangerman et al. [12] and also Przyjazny [11] studied the sorption capacities of Tenax GC towards highly volatile sulfur compounds at lower adsorption temperatures. With the goal of measuring volatile sulfur compounds in human breath, Tangerman found that the capacity of the Tenax trap tubes is increased to a large extent by keeping the trap tubes in dry ice $\left(-70^{\circ} \mathrm{C}\right)$ or in liquid nitrogen $\left(-196^{\circ} \mathrm{C}\right)$. This was especially the case for hydrogen sulfide adsorption. The minimum amount of sulfur gases that could be detected by gas chromatography employing a glass column packed with $20 \%$ SE-30 on Chromosorb P and an FPD was approximately $0.2 \mathrm{ng} / \mathrm{L}$ (0.1 ppb). The same technique: cryogenic Tenax trapping (liquid nitrogen, $\left.-196^{\circ} \mathrm{C}\right)$, thermal desorption $\left(200^{\circ} \mathrm{C}\right) / \mathrm{GC} / \mathrm{FPD}$ was later used by the same author [13] to determine simultaneously a large 
group of volatile sulfur gases: $\mathrm{H}_{2} \mathrm{~S}, \mathrm{COS}, \mathrm{CS}_{2}$, thiols, sulfides, disulfides in ambient air. To prevent build-up of water in the Tenax tube at these low temperatures, the water was pretrapped by passsing the gas through a dessicant (calcium chloride) which was found not to adsorb any of the sulfur-containing volatiles [13]. The experimental recoveries were relatively high (around 92\%) and the author could detect volatile sulfur gases in air at the ppt level, although no concrete detection limits were quoted. Problems were only found in the determination of $\mathrm{SO}_{2}$. Preconcentration of this component onto Tenax at $-196^{\circ} \mathrm{C}$ followed by GC analysis resulted in a complete loss of this component. Probably, in spite of the use of calcium chloride drying tubes, traces of water react with $\mathrm{SO}_{2}$ in the Tenax tube or in the $\mathrm{GC}$ column, thereby preventing its detection.

Later, when analyzing low-boiling organic sulfur compounds (MeSH, DMDS, CS2) in anoxic lake-water Henatsch et al. [14] used cryoadsorption on Tenax tubes followed by analysis on a UCON coated glass capillary column and FPD detection. Due to the sensitivity differences of the FPD for the individual sulfur compounds different detection limits were found, $\mathrm{CS}_{2}$ was detectable with a lowest limit of $5 \mathrm{ng} / \mathrm{L}$. The detection limits of MeSH and DMDS were around $50 \mathrm{ng} / \mathrm{L}$. One of the features of this process is that the disturbance of the procedure by excessive amounts of methane also present in the anoxic sample was avoided by using solid carbon dioxide rather than liquid nitrogen to cool the cryotraps. A schematic representation of the instrumentation developed by Henatsch and Jütner is shown in Figure 1. The water-trap (part D in Figure 1) was constructed by using two 1-mL pipette tips connected end-to-end by silicone tubing. This trap was introduced into the gas line and cooled with solid carbon dioxide. It was shown that the sulfur compounds were not retained in this trap.

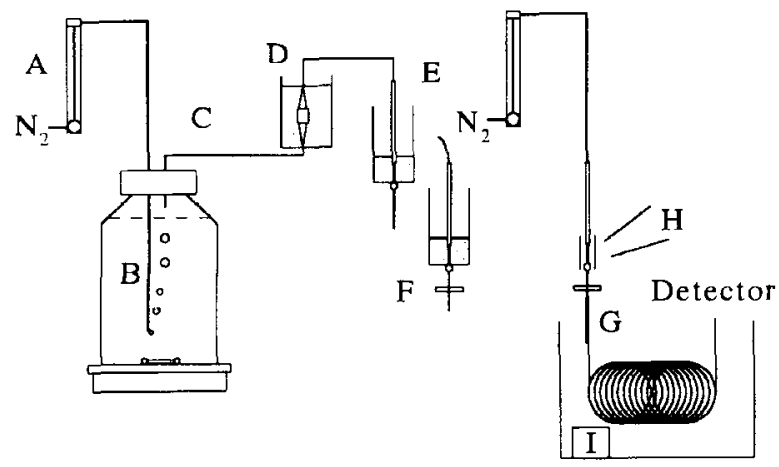

Figure 1

Cryotrapping system for the preconcentration of volatile organic sulfur compounds. $A=$ Rotameter for regulation of the nitrogen gas flow $(180 \mathrm{~mL} / \mathrm{min})$ during purging the water sample and thermal transfer $(20 \mathrm{~mL} / \mathrm{min})$ of the compounds onto the $\mathrm{GC}$ column; $\mathrm{B}=$ injection needle; $\mathrm{C}=$ exit needle; $\mathrm{D}=$ water-trap; $\mathbf{E}=$ cryotrap (Tenax TA), both cooled with carbon dioxide; $F=$ cryotrap connected to the GC system; $G=$ thermal transfer of the compounds onto the capillary column by rapid heating of the cryotrap with a heating gun (H). For the transfer, the GC oven was cooled to $0^{\circ} \mathrm{C}$. PTFE tubes were fixed to the individual parts of the arrangements with silicone tubing. Reprinted with permission granted by Elsevier Science Publishers BV from "Capillary gas chromatographic analysis of low-boiling organic sulphur compounds in anoxic lake-water by cryoadsorption" by J.J. Henatsch and F. Jüttner, Journal of Chromatography, Vol. 445, p. 95-105 (1988).

Several experiments of cryogenic absorption of sulfur gases on unpacked sorption tubes were also described. In these cases, liquid argon [15], nitrogen [16], oxygen [17] were used to cool the deactivated Pyrex glass or Teflon trap tubes. Hot water ensured desorption into the chromatographic system. Flame photometric detectors or even mass spectrometers were used to detect the sulfur gases tested at sub ppb concentrations.
From the literature study described above, it is clear that several materials are capable of adsorbing sulfur species with large breakthrough volumes. Whether these materials provide sufficient sulfurto-hydrocarbon selectivity yet remains to be established.

\section{Chromatographic Separation}

The second step in GC-based analytical procedures for the determination of sulfur components in natural gas is the separation of the individual sulfur components. The separation efficiency recuired depends on both the performance of the selective enrichment step as well as on the selectivity of the detector. If non-sulfur containing species are removed quantitatively in the sample pretreatment step. a separation of the individual sulfur components solely is sufficient. The same holds for the case that a truely selective, quenching-free detector is employed. In more realistic cases where both the sample pretreatment and the detection step are not $100 \%$ selective, separation of only the individual sulfur species is no longer adequate. Now all sulfur peaks should not only be separated from each other but also from all other components that might perturb measurements. For a successful and complete separation of a mixture covering such a wide range in boiling points as sulfur compounds in natural gas, it is very important to have a suitable column or system of columns for separation. If the separation performance is found to be insufficient due to poor resolution or to a too long analysis time, combination of two or more columns with or without switching valves could be an alternative. Details of these approaches and an overview of advantages and/or disadvantages of the individual techniques will be reviewed subsequently.

\subsection{Packed-Column Systems}

One of the advantages of packed columns over capillary columns is the high sample capacity of packed systems, which makes it possible to inject large sample volumes. On the other hand, however, packed columns generally suffer from a low resolving power. For sulfur analysis this means that only a limited number of sulfur gases can be simultaneously separated on a single column. Moreover, there is a serious risk of adsorption losses on the column due to the adsorptive nature of sulfur components on the one hand, and the limited inertness of packed columns on the other hand. As column materials, Teflon or properly deactivated glass are usually the materials of choice due to the activity of volatile sulfur compounds and their strong tendency to adsorb onto glass and/or metal surfaces which can cause peak tailing and sometimes complete losses of trace sample components. Thus, it is essential to deactivate the glass and metal surfaces of a chromatographic system or to use only Teflon columns and connections to minimize both peak tailing and losses incurred by irreversible adsorption of low concentrations of sulfur-containing compounds.

In the ISO methods for the GC determination of individual sulfur components in natural gas packed GC columns are used exclusively. ISO method 6326-2 uses a glass or teflon column packed with two stationary phases. The first two thirds of the column is packed with $40 \%$ silicone oil DC 200 on Chromosorb W and the last one third is packed with $40 \%$ dinonylphthalate on the same support. The separation strength of this column is limited. Accurate quantification of for example hydrogen sulfide and methylmercaptan is only possible if the ratio of the concentrations of these components is below approximately 10 . ISO method $6326-4$ is based on the use of a glass or teflon column packed with 80-100 mesh polystyrene/divinylbenzene porous polymer beads. With this column a good resolution between the components of interest is achieved. Various chromatographic columns optimized for the separation of 
sulfur containing components have been descibed in literature. A short overview of these systems is presented below.

Stevens [18] described the use of a 36-feet Teflon column packed with Teflon powder coated with $1 \%$ polyphenyl ether and orthophosphoric acid and succeeded in analyzing $\mathrm{H}_{2} \mathrm{~S}_{1} \mathrm{SO}_{2}$ and mercaptans at the ppb level using a GC system equipped with an FPD. Following this example Bruner et al. [19] also used a small amount of orthophosphoric acid (0.5\%) mixed with $0.3 \%$ Dexsil 300 as a non-polar, low-bleeding liquid phase. Now, however, Graphon, a type of graphitized carbon black was used as solid support for packing a $1.25 \mathrm{~m} \times 3 \mathrm{~mm}$ i.d. Teflon column. Orthophosphoric acid increased the retention time of $\mathrm{H}_{2} \mathrm{~S}$ and $\mathrm{SO}_{2}$, which only have a weak interaction with the pure Graphon surface, while the Dexsil 300 reduces the surface area of the adsorbent. In this way the retention times of the compounds under examination are compressed into a smaller elution window. With such a column, operated isothermally at $40^{\circ} \mathrm{C}, \mathrm{H}_{2} \mathrm{~S}$ and $\mathrm{SO}_{2}$ could be detected on an FPD at minimal detectable concentrations of 20 and $10 \mathrm{ppb}$, respectively.

Later, $\mathrm{H}_{2} \mathrm{~S}$ and COS were detected in a mixture of hydrocarbons and inorganic gases ( $\mathrm{CO}, \mathrm{CO}_{2}, \mathrm{~N}_{2}$ and $\left.\mathrm{O}_{2}\right)$ by Suier and Hill [20]. These authors used the observation from the work by de Souza et al. [21] that a column packed with acetone-washed Porapak OS gave a good separation of $\mathrm{H}_{2} \mathrm{~S}$ and $\mathrm{COS}$ and from the work by Burgett [22], that $\mathrm{COS}, \mathrm{H}_{2} \mathrm{~S}$, and $\mathrm{SO}_{2}$ could be determined in the sub-ppm range using a column packed with acetone-washed Porapak coated with $0.5 \% \mathrm{H}_{3} \mathrm{PO}_{4}$. In their own experimental work, Suier and Hill used a Teflon-coated stainless steel column packed with Porapak OS to separate a slightly more complex mixture and improved this procedure by adding a short ( 3 feet) precolumn packed with Porapak $R$ to achieve adequate separation of $\mathrm{H}_{2} \mathrm{~S}$ and $\mathrm{SO}_{2}$ from interfering water. Separation between the COS and the water peak was improved by temperature programming the column at a slow rate, i.e. subambient initial temperature $-65^{\circ} \mathrm{C}(3 \mathrm{~min})$ to $10^{\circ} \mathrm{C}$ at $30^{\circ} / \mathrm{min}$, then to $92^{\circ} \mathrm{C}$ at $5 \% \mathrm{~min}$, then at $30^{\circ} / \mathrm{min}$ to $170^{\circ} \mathrm{C}$, allowing the COS to elute before the elution of the water began. A thermal conductivity detector was used but no detection limits were quoted. The separation was relatively slow. The total analysis time was 45 minutes.

All columns described above could separate only a limited mixture of sulfur compounds. Tailing was frequently observed when trying to detect other components. De Souza [23] tried to resolve this problem by using a special packing material: Supelpak-S, i.e. acetone-washed Porapak OS. This author reported a number of advantages of a column packed with this material: (i) water (present in many fuel gases and also in natural gas) and other highly polar molecules are quickly eluted from the column and do not interfere with the separation of the sulfur gases; (ii) a very short-length (only $48 \mathrm{~cm}$ effective length) is required, hence, low inlet pressures are employed; (iii) the column has a high resolving power; (iv) the column can be temperature programmed to as high as $230^{\circ} \mathrm{C}$; (v) no liquid phase is used because the porous nature of the bead packing serves the function of both the liquid phase and the solid support, hence, column bleeding is low; (vi) symmetrical peak shape for $\mathrm{SO}_{2}$; and (vii) the column can separate $\mathrm{H}_{2} \mathrm{~S}$ from COS and all other sulfur gases tested. Typical chromatograms obtained with and without pretreatment of Porapak OS are shown in Figure 2.

For the separation of individual sulfur gases in several different matrices e.g. $\mathrm{CO}_{2}$, ambient air, fresh lake water etc. using a single packed column set-up a number of other packing materials were investigated: Porapak OS coated with $5 \%$ silicone oil $\mathrm{OF}-1$ or Chromosorb $\mathrm{G}+5 \%$ polyphenyl ether [24], silica gel or Porapak $\mathrm{R}$
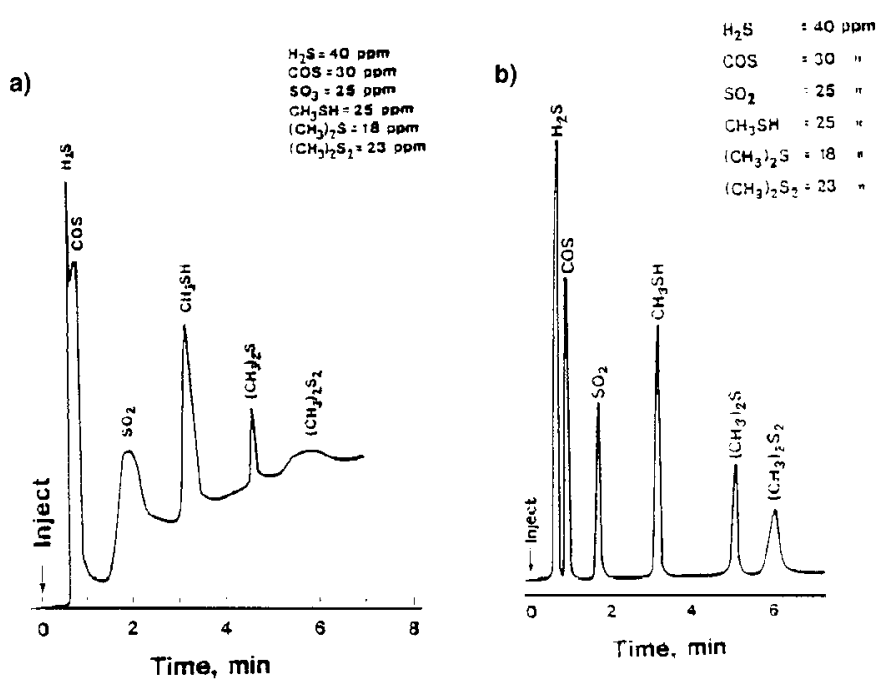

Figure 2

Typical chromatograms obtained without (a) and with (b) acetone washing of Porapak QS. GC conditions: carrier gas He $30 \mathrm{~mL} / \mathrm{min}$; sample volume $2 \mathrm{~mL}$; FPD temperature $115^{\circ} \mathrm{C}$; detector gases hydrogen $155 \mathrm{~mL} / \mathrm{min}$, oxygen 15 $\mathrm{mL} / \mathrm{min}$ and air $50 \mathrm{~mL} / \mathrm{min}$; temperature program: $30^{\circ} \mathrm{C}(1 \mathrm{~min})$ to $210^{\circ} \mathrm{C}(4$ $\mathrm{min}$ ) at $30 \% \mathrm{~min}$. Reprinted from the Journal of Chromatographic Science: "Supelpak-S: The GC Separating Column for Sulfur Gases"by T.L.C. de Souza, Vol. 22 pp. $470-472$ (1984) by permission of Preston Publications, A Division of Preston Industries, Inc.

without liquid phase [25], acid-washed Porapak Q [26], Chromosorb W AW DMCS coated with 15\% SF-96 and 6\% OV-225 [27], Chromosil 310 [28], Chromosorb G coated with Triton X305 [29], Tenax GC [30], Diatomite CO coated with 30\% Triton X-305 [31], Chromosorb W ASTM with 15\% OV-17 [32]. The detection limits range from ppm to $\mathrm{ppb}$ and sub-ppb level depending on the detector employed.

In most cases the column material used for sulfur separations was Teflon and/or Teflon coated aluminum or deactivated glass. It is generally stated that the use of bare metal or glass has to be avoided because of the strong tendency of active sulfur compounds to adsorb onto metal and glass surfaces. A notable exception in this respect is Pearson [24], who concluded contranily and rejected Teflon in favour of stainless steel when he tried to determine $\mathrm{C}_{1}-\mathrm{C}_{4}$ mercaptans and sulfides in natural gas. According to Pearson, stainless steel columns and connections are much more robust and cause less problems with absorption than Teflon. Pearson could detect 0.1 ppm of tertiary butyl mercaptan and concluded that this technique is specific for sulfur compounds.

\subsection{Capillary-Column Systems}

Although several types of packed columns have been used in the gas chromatographic measurements of various sulfur-containing gases at concentrations down to approximately 5 ppm, packed columns are plagued with several disadvantages: (i) large surface areas and concomitant adsorption losses; (ii) a gradual approach to equilibration and the corresponding need to perform a number of "conditioning" injections both before and during the working period in order to obtain stable responses; (iii) inadequate resolution for certain important compounds in mixtures of sulfur-containing gases (e.g. $\mathrm{H}_{2} \mathrm{~S}$ and COS); (iv) relatively high pressure drops due to the long column length and the low permeability; and (v) considerable potential for hydrocarbon quenching of the FPD's response due to inadequate peak resolution between the sulfur compounds and other organic constituents of the samples. Because of these inherent limitations of packed columns, glass capillary wall-coated open tubular (WCOT) columns were investigated for their potential utility 
in the GC determination of sulfur-containing gases. Although glass columns are clearly more inert than packed columns they can still exhibit a substantial amount of residual surface activity. Various methods for deactivation of glass surfaces have been reported. Blomberg [33] used glass capillary columns deactivated by a thin layer of non-extractable Carbowax 20M coated with SF-96 to analyze the gas phase of fresh tobacco smoke. The detection limit, achieved with FPD, was 40 pg of sulfur. In capillary columns, the retention times of inorganic sulfur gases such as $\mathrm{H}_{2} \mathrm{~S}$ and COS are reduced dramatically, hence, cryogenic temperature programming is often necessary [33]. Farwell et al. [17] evaluated the deactivation of borosilicate glass WCOT columns with several materials such as SE-30, Carbowax 20M, OV-17, OV-101 and SE-54. These authors found that the first three reagents caused broadening and tailing of the sulfur gases under investigation. Only the two latter reagents showed sufficient efficiency for high resolution separations (Figure 3). For some other components, the results achieved by capillary chromatography were found to be unsatisfactory. For example, $\mathrm{SO}_{2}$ always produced broad, tailing peaks on a variety of glass and fused-silica open tubular (FSOT) capillary columns. Depending upon the particular column and/or temperature program, MeSH also yielded a distorted, unsymmetrical peak with either a leading or tailing edge. These problems are caused not only by residual active surface sites of capillary columns but could also be caused by carrier gas impurities, such as water, as Barinaga and Farwell reported in a later publication [34], in which they also suggested a procedure to minimize these water effects by adding a dryer cartridge packed with $5 \AA$ Molecular Sieve between the carrier gas purifier and the injection valve

a)

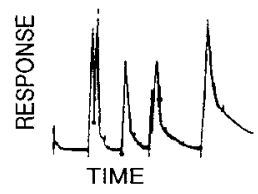

Figure 3

Influence of pretreatment of chromatographic packing materials on the sulfur elution pattern. Chromatograms obtained with undeactivated (a), SE-30 WCOT (b), and OV-101 WCOT (c) capillary columns, respectively. Elution order: $\mathrm{H}_{2} \mathrm{~S}$, COS, MeSH, DMS, CS 2 and DMDS. Chromatographic conditions: $u=20.4 \mathrm{~cm} / \mathrm{s}$ of helium, oven programmed from $-70^{\circ} \mathrm{C}$ to $150^{\circ} \mathrm{C}$ at $16 \% \mathrm{~min}$. Reprinted with permission from "Determination of Sulfur Containing Gases by a Deactivated Cryogenic Enrichment and Capillary Gas Chromatographic System" by $S$. $O$. Farwell, S.J. Gluck, W.L. Bamesberger, T.M. Schutte, and D.F. Adams, Analytical Chemistry, Vol. 51, No. 6, pp. 609-615. Copyright 1979 American Chemical Society.

Although the use of glass and FSOT capillary columns provides a greater inertness, better peak shapes, lower detection limits, and little or no memory effects, capillary columns also suffer from certain disadvantages. One of those disadvantages is that the volumetric flow rate of the preconcentration device may be incompatible with that of the capillary column. For example, the 0.5 to $2 \mathrm{~mL} / \mathrm{min}$ carrier gas flow for capillary columns is not compatible with the common desorption flow rate of many solid adsorbent traps. Capillary cryofocusing and cryotrapping techniques are not effective for poorly retained, low $k$ solutes like $\mathrm{H}_{2} \mathrm{~S}, \mathrm{COS}$, and $\mathrm{SO}_{2}$ that can break through the capillary cryotrapping or cryofocusing region. Also in the case of atmospheric sampling, microgram amounts of $\mathrm{CO}_{2}$ and/or water collected in the preconcentration device can occlude the capillary cryofocusing and cryotrapping region. This causes incomplete analyte transfer and overpressurisation of the column upon injection resulting in losses of analytes due to flash-back of the loop contents into the upstream system and consequent exposure to active surface sites. Another disadvantage of capillary columns is the extreme demands placed on the dead volume and the actual transducing region of the detectors. A third disadvantage is the low initial oven temperatures, $-50^{\circ}$ to $-70^{\circ} \mathrm{C}$, required to obtain baseline separation between the unretained peak $\left(\mathrm{CO}_{2}\right)$ and the early eluting compounds $\mathrm{H}_{2} \mathrm{~S}$, COS and $\mathrm{SO}_{2}$ on thin film non-polar columns. The necessary subambient initial oven temperature can only be produced by costly and logistically inconvenient cryogenics, such as liquid nitrogen. To overcome these disadvantages and to achieve baseline separation of sulfur gases at ambient temperatures as well as to increase sample throughput by decreasing the elution times, Barinaga and Farwell [35] explored the use of widebore, thick-film FSOT columns and "phase tuning" to optimize selectivity. Wide-bore, $0.5 \mathrm{~mm}$ i.d. FSOT columns have been recommended for certain separations because of their higher sample capacity and shorter analysis times at higher carrier gas flow rates compared to narrow-bore columns. Likewise, stationary phase films of greater thickness ( 1 to $8 \mu \mathrm{m}$ ) have been used in special situations for their greater capacity and, as a consecuence, greater retention of very volatile compounds. A thick film non-polar column connected to a short length of a more polar column was used to eliminate the necessity of subambient initial oven temperatures while maintaining baseline separation of the commonly occurring sulfur gases. The best results were obtained using a column system consisting of a $30 \mathrm{~m} \times 0.53 \mathrm{~mm} \mathrm{DB}-1, d_{\mathrm{f}}=5 \mu \mathrm{m}$ coupled to a $3 \mathrm{~m} \times$ $0.53 \mathrm{~mm}$ DB WAX, $d_{\mathrm{f}}=1 \mu \mathrm{m}$. This column combination, equipped with a modified FPD [35] to decrease the dead volume and improve the streamlining, and operated in the temperature programmed mode: initial temperature: $30^{\circ} \mathrm{C}(1.2 \mathrm{~min})$ to $140^{\circ} \mathrm{C}$ at $30^{\circ} / \mathrm{min}$ can achieve baseline separation of all seven sulfur gases $\mathrm{H}_{2} \mathrm{~S}, \mathrm{COS}, \mathrm{SO}_{2}$ MeSH, DMS, $\mathrm{CS}_{2}$, DMDS and $\mathrm{CO}_{2}$ within a total elution time of less than 5 minutes (Figure 4)

Porous-layer open-tubular (PLOT) columns with PoraPLOT Q deposited on the column wall have become commercially available Jacobsson et al. [36] found that PLOT columns can take advantage of both the selectivity of the solid adsorbent material deposited as a thin layer on the wall and of the large plate numbers that are

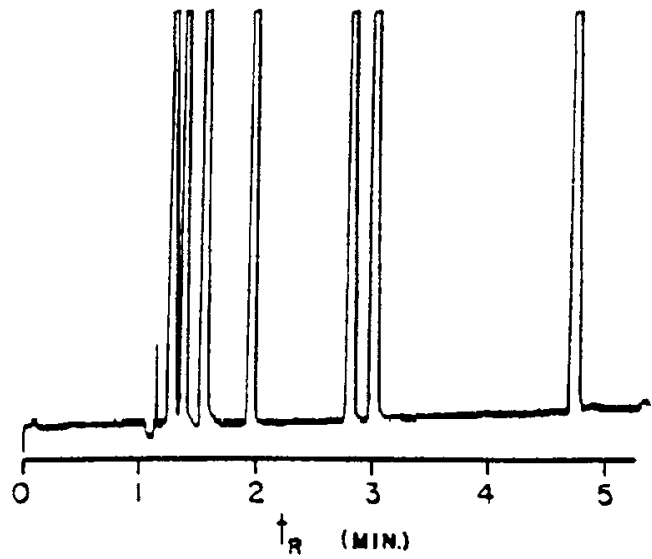

Figure 4

Chromatogram of cryogenically collected sulfur gases obtained at ambient initial oven temperature. Mixed phase column: $30 \mathrm{~m} \times \mathbf{0 . 5 3} \mathrm{mm}$ DB-1, $d_{4}=\mathbf{5} \mu \mathrm{m}$ coupled to $3 \mathrm{~m} \times 0.53 \mathrm{~mm}$ DB WAX, $d_{4}=1 \mu \mathrm{m}$; elution order: air, $\mathrm{CO}_{2}, \mathrm{H}_{2} \mathrm{~S}, \mathrm{COS}$, $\mathrm{SO}_{2}, \mathrm{MeSH}, \mathrm{DMS}, \mathrm{CS}_{2}$, and DMDS. Reprinted with permission granted by Hüthig GmbH from "Noncryogenic FSOT Column Separation of Sulfur-Containing Gases"by C.J. Barinaga and S.O. Farwell, Journal of High Resolution Chromatography \& Chromatographic Communication, Vol. 10, p. 538 (1987). 
Table 1

Detection limits for sulfur species on the PoraPLOT $U$ column. Detectors: FPD and SCD. Column length $12.5 \mathrm{~m}$. Reproduced with permission granted by Hüthig GmbH from "Evaluation of the PoraPLOT U FSOT Column for Sulfur Gases" by K.K. Gaines, W.H. Chatham, and S.O. Farwell, Journal of High Resolution Chromatography, Vol. 11, p. 585 (1990).

Detection limits $(\mathrm{pg})$

Component

\begin{tabular}{lrr} 
& FPD & SCD \\
\hline $\mathrm{COS}$ & 30 & 5 \\
$\mathrm{CS} 2$ & 110 & 20 \\
$\mathrm{DMDS}$ & 660 & 30 \\
$\mathrm{DMS}$ & 160 & 30 \\
$\mathrm{H}_{2} \mathrm{~S}$ & 2000 & 760 \\
$\mathrm{MeSH}^{\mathrm{SO}}{ }_{2}$ & 850 & 190 \\
& 850 & 270 \\
\hline
\end{tabular}

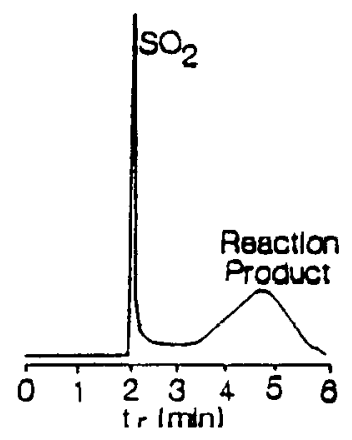

Figure 5

Reaction of sulfur dioxide on the PoraPLOT column. Detector: sulfur chemiluminescence. Reprinted with permission granted by Hüthig GmbH from "Evaluation of the PoraPLOT U FSOT Column for Sulphur Gases" by K.K Gaines, W.H. Chatham, and S.O. Farwell, Journal of High Resolution Chromatography, Vol. 11, p. 585 (1990).

generated by capillary columns. Moreover, the use of PLOT columns was found to be highly compatible with mass spectrometry. Jacobsson succeeded in determining $\mathrm{H}_{2} \mathrm{~S}$ in liquid and solid samples at sub-pg levels. Similarly, Gaines et al. [37] evaluated the PoraPLOT U FSOT column for determination of the seven common sulfur gases listed above. With a temperature program of: $80^{\circ} \mathrm{C}(2$ min) to $180^{\circ} \mathrm{C}$ at $30^{\circ} / \mathrm{min}$ in combination with an FPD and a sulfur chemiluminescence detector (SCD), they achieved detection limits in the $\mathrm{pg}-\mathrm{ng}$ of $\mathrm{S}$ range for the individual sulfur compounds. However, $\mathrm{H}_{2} \mathrm{~S}$ was very reactive towards the stationary phase and $\mathrm{SO}_{2}$ showed some chemical derivatization on the column (Table 1 and Figure 5). Therefore, the PoraPLOT U column is not useful for low ppb/ppt analysis of $\mathrm{H}_{2} \mathrm{~S}$ and $\mathrm{SO}_{2}$. Nevertheless, it is suitable for the determination of $\mathrm{COS}_{1} \mathrm{CS}_{2}, \mathrm{DMDS}$, and DMS at concentrations down to the ppt range, while $\mathrm{H}_{2} \mathrm{~S}$ and $\mathrm{SO}_{2}$ can be successfully analyzed on this column at higher $\mathrm{ppb} / \mathrm{ppm}$ concentrations

For the analysis of odorants and natural gas sulfur compounds Russo and Maghini [38] used a fused-silica capillary column: $50 \mathrm{~m}$ $\times 0.2 \mathrm{~mm}$ i.d. $d_{f}=0.3 \mu \mathrm{m}$ (crosslinked methyl silicone film). To perform the specific analysis, two different runs had to be performed. A temperature programmed analysis $\left(35^{\circ} \mathrm{C}(10 \mathrm{~min})\right.$ to $250{ }^{\circ} \mathrm{C}$ at $7 \% \mathrm{~min}$ ) was used for the analysis of mercaptans and sulfides, while $\mathrm{H}_{2} \mathrm{~S}$ and $\mathrm{COS}$ were analyzed isothermally at $-15^{\circ} \mathrm{C}$. Highly purified helium was used as carrier gas.

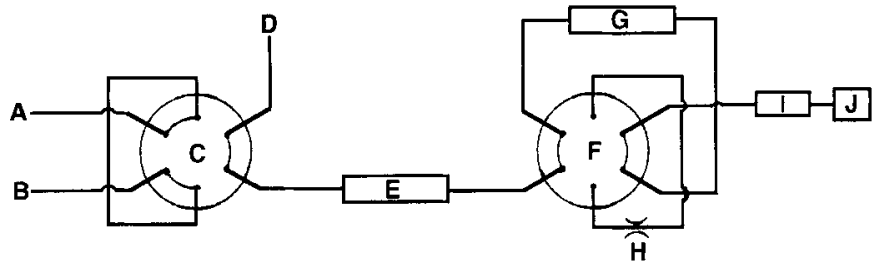

Figure 6

Schematic diagram of valve and column layout designed by Monks.

A - sample in; $B$ - sample out; $C$ - 6 -port sampling valve; $D$ - carrier gas in; $E$ - analytical column; $F-6$ port valve; $G$ - bypass column; $H$ - bypass needle valve; I - butfer column; $\mathbf{J}$ - detector. Reprinted with permission granted by Elsevier Science Publishers BV from "Determination of Sulphur Compounds in Natural Gas" by S.E.A. Monks, Proceedings of the Congress of "Gas Quality - Specification and Measurement of Physical and Chemical Properties of Natural Gas", Groningen, The Netherlands, 22 - 25 April 1986, Elsevier, Amsterdam, The Netherlands, 1986, p. 641.

Monks [39], on the other hand, achieved complete determination of sulfur components in natural gas by using a multi-packed-column system operated isothermally at $115^{\circ} \mathrm{C}$. A schematic representation of this system is shown in Figure 6 . Separation of sulfur compounds from hydrocarbons is achieved on a main column with a length of $1 \mathrm{~m}$. This column is packed with acetone-washed Porapak PS. The bypass column, which is $2 \mathrm{~m}$ long packed with acetone-washed Porapak OS, is used to selectively isolate some of the sulfur components during the analysis. A $0.25 \mathrm{~m}$ buffer column packed with acetone-washed Porapak QS is placed immediately before the detector to damp pressure surges caused by valve switching. A compromise that had to be made with this system involves the separation of tertiary butyl mercaptan from methyl ethyl sulfide, an indigenous component of natural gas. In order to keep the analysis time as short as possible these components elute together at about $5.3 \mathrm{~min}$. The total analysis time is $15 \mathrm{~min}$. The detection limits vary between 0.05 and $70 \mathrm{ppm}$.

Obbens et al. [40] reported another alternative for the $\mathrm{GC}$ analysis of sulfur components in natural gas with a combination of packed and capillary columns installed in two independently, thermostatically controlled, heated compartments. Separation of $\mathrm{H}_{2} \mathrm{~S}$ and $\mathrm{SO}_{2}$ was performed on an acetone-washed Porapak QS packed column loaded with $0.5 \% \mathrm{H}_{3} \mathrm{PO}_{4}$ to increase inertness and to prevent tailing of $\mathrm{H}_{2} \mathrm{~S}$. The separation of THT and other sulfur compounds was achieved on a very thick-film $50 \%$ phenyl-methyl silicone phase on a FSOT capillary column. The last two techniques described above have employed an FPD for detection of the eluted sulfur compounds.

From the literature survey presented in this chapter it can be concluded that future research in the area of sulfur separation for natural gas analysis should be directed towards the development of separation systems that enable both a separation of the individual sulfur peaks and, more importantly, separation of sulfur peaks and interfering hydrocarbons. To date, no such system is available

\section{Detection Systems for GC-Based Sulfur Analysis}

One of the major advantages of gas chromatography is the availability of a large number of sensitive universal as well as selective detectors. The combination of the excellent separation capability of (capillary) GC with sensitive selective detection enables the measurement of low concentrations of different components in sample matrices of ever increasing complexity. Selective detectors are becoming increasingly popular in recent years. Not only for the fact that they partially eliminate the need for laborious and time consuming methods for sample preparation, the use of a selective 
detection device also reduces the risk of false-positive identifications. It is evident that also the separation itself is simplified if selective detectors are employed. Selective detection enables target compounds to be measured while other coeluting compounds are not sensed. Important universal detectors are the flame ionization detector (FID) and the thermal conductivity detector (TCD). As these detectors respond to virtually all components amenable to GC, high demands are posed on sample preparation and separation. For non-hydrocarbon compounds containing for example sulfur, nitrogen or phosphorous, a wide range of selective detectors is available. For the selective detection of sulfur this includes the flame photometric detector (FPD), the sulfur chemiluminescence detector (SCD), atomic emission detector (AED), photo ionization detector (PID), electron capture detector (ECD), mass spectrometric (MS) detection devices and detection techniques based on electrochemical principles such as the Hall electrolytic conductivity detector (HElCD) and coulometric detection devices. The basic principles of the various detection systems for $\mathrm{GC}$ as well as the hardware requirements are the subject of a series of books and review articles [41-44]. An excellent review article of potential gas chromatographic sulfur-sensitive detectors in environmental analysis has been published by Wardencki and Zygmunt in 1991 [45]. In the present review only improvements that have been achieved after this date will be discussed. In spite of the fact that most of the sulfur selective detectors are already available for many years, considerable improvements in the performance of especially the FPD and the SCD have been achieved in the last three years.

\subsection{Improvements in Flame Photometric Detection}

The FPD is nowadays the most widely used sulfur-selective detector for GC. Present-day systems are mostly based on the work of Brody and Chaney [46] published some 30 years ago. The FPD is basically a flame emission photometer. Sulfur compounds, burnt in a hydrogen-rich flame, produce $\mathrm{S}_{2}{ }^{*}$ which emits radiation near 400 $\mathrm{nm}$. This radiation is monitored by a photomultiplier tube. Although the role of $\mathrm{S}_{2}{ }^{*}$ as a main emitter in FPD has not been totally unambiguous [47], the $\mathrm{S}_{2}{ }^{*} / \mathrm{S}_{2}$ mechanism is now widely accepted and used to explain the square root dependence of the detector response towards the concentration of sulfur compounds tested. Although rather sensitive, the FPD suffers from a number of inherent problems such as non-linear response; dependence of the response factor on molecular structure; and quenching by hydrocarbons and other species coeluting with the sulfur compounds.

The most serious problem in the practical application of the FPD is the quenching effect. Although the exact cause of quenching remains yet to be established, it appears that both the change in the flame temperature as well as in the flame chemistry that occur when large amounts of hydrocarbons are introduced in the flame play a role. Vanious instrumental changes to reduce the susceptibitity of the FPD for quenching have been proposed in literature. Patterson et al [48] developed the dual flame photometric detector. In this detector components eluting from the GC column are burnt in a hydrogen rich first flame. In a second flame $\mathrm{S}_{2}{ }^{*}$ species emit light which is than measured on the photomultiplier tube. As all components are burnt in the first flame, the flame chemistry of the second flame is much less affected by coelution of sulfur and non-sulfur containing components. As a result of this the dual-flame mode FPD resists quenching and is more truly quadratic in response. Unfortunately, however, the sensitivity of the dual flame FPD is only approximately $10 \%$ to $20 \%$ of that of the single flame version [49]. Moreover, dual flame operation enhances hydrocarbon response. The selectivity of sulfur versus carbon of the dual flame FPD is only $10^{3}$ to $10^{4}$ as opposed to a selectivity of $10^{5}$ to $10^{6}$ for the single flame
FPD [50]. Because the poor selectivity of the dual flame FPD (D-FPD) the analysis of individual $\mathrm{S}$ compounds in a complex hydrocarbon mixture is complicated by the simultaneous hydrocarbon response. A method to overcome this difficulty has been published by Baig et al. [50]. In the method designed by these authors the effluent of the column is split into two streams. One stream is fed to the D-FPD, the second to an FID. Next, the FID signal is subtracted from the D-FPD signal which results in a simplified chromatogram as the hydrocarbon response is eliminated

A fully chromatographic approach for eliminating quenching of the FPD was described by Efer et al. [51]. These authors used a seriescoupled system of two capillary columns with different polarities to achieve selectivity tuning. By varying the mid-point pressure settings overlap of sulfur-containing and sulfur free components could be controlled, resulting in quenching free chromatograms or at least chromatograms that contain quenching free regions. Efer also applied this set-up for detailed studies of the magnitude of the quenching effect. When studying the degree of quenching of ethylthiophene by nonane, it was found that a ten-fold excess of the quenching compound was required to obtain a significant signal reduction. The relationship between signal reduction and the concentration of the quenching component was found to be non-linear. Similar studies by Liu et al. [52] revealed that the decrease of the sulfur signal caused by flame hydrocarbons is strongly dependent on the oxygen to hydrogen ratio in the flame and, under certain conditions, also on the sulfur to carbon ratio of the sample. Higher $\mathrm{O} / \mathrm{H}$ ratios decrease the quenching effects as well as the dependence of this quenching on the $\mathrm{S} / \mathrm{C}$ ratio in the sample. The detection limit of the FPD is about $10^{-11} \mathrm{~g} \mathrm{~S} / \mathrm{s}$, which provides mass detection limits in the sub-nanogram range.

Apart from quenching also the limited linearity and selectivity of the FPD can hamper its use in practical applications. A series of other papers have been published in literature in which important methods for improving the linearity and the selectivity are described. A numbers of authors [53-55] proposed the use of dopants such as $\mathrm{SO}_{2}$ or $\mathrm{CS}_{2}$ to linearize the detector output. The difficulty with this procedure is that the dynamic range is reduced and the linear output is dependent on the dopant and the solute. Sevcik and Phuong Thao [56] have evaluated the selectivity of the FPD and suggested that the unsuitable geometry of the interference filters resulted in interference from hydrocarbons and heteroatoms. They found that the selectivity of the detector improved with respect to hydrocarbon and heteroatom interference when the flame output was collimated. Aue et al. improved the sulfur selectivity by about one to three orders of magnitude by using a dual-channel FPD, which annulled the response of carbon or other elements by differential operation; or by having the CONDAC ("conditional access" or "conditional acceptance") algorithm deny unwanted elements access to the chromatogram [57]. The two-channel and CONDAC chromatograms of the compounds under investigations are shown in Figure 7. In their own experiments Aue et al. preferred to use the FPD "open", i.e. free of spectral discrimination beyond the response profile of the photomultiplier tube.

An approach to obtain a truely linear relationship between the FPD output signal and the sulfur concentration was published by Aue and Sun [58]. Experimental work by these authors confirmed that although the luminescence from sulfur compounds in the FPD is dominated by the $\mathrm{S}_{2}$ main-system bands (of approximately quadratic response), it also contains a linear emitter with a "spectrum" in the 600 to $850 \mathrm{~nm}$ region. Up till now in the spectra of conventional quadratic emissions (Figure 8) no emission beyond $520 \mathrm{~nm}$ had been measured. For that reason the linear sulfur emission had 


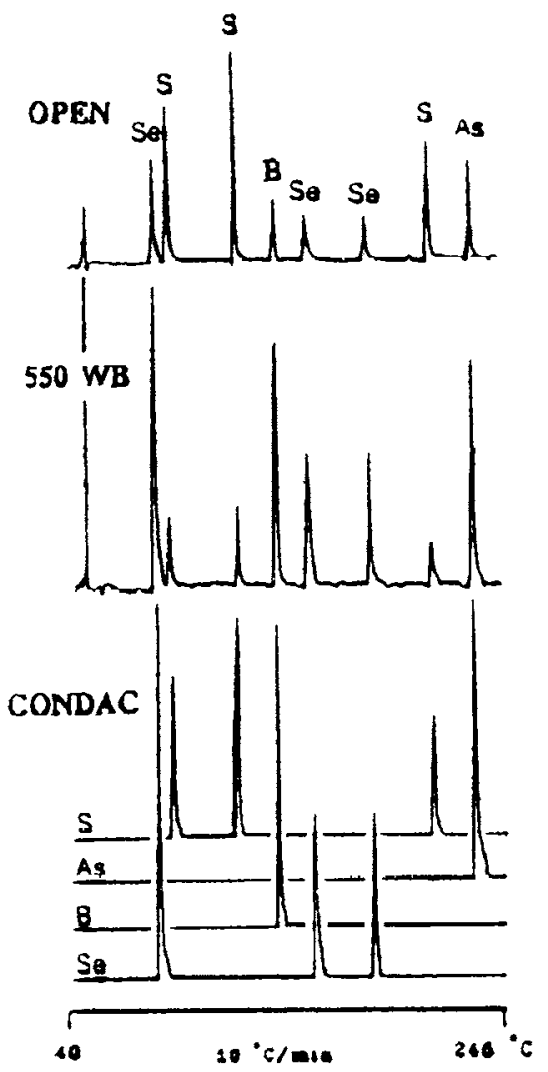

Figure 7

Flame photometric detection of various elements using differential operation and CONDAC algorithm. Two-channel and CONDAC chromatograms of (in order of elution) $14 \mathrm{ng}$ dimethyldiselenide, $1.0 \mathrm{ng}$ diethyl disulfide, $1.6 \mathrm{ng}$ di-tert-butyldisulfide, $100 \mathrm{ng}$ o-carborane, $20 \mathrm{ng}$ methyl-benzselenazole, $15 \mathrm{ng}$ diphenylselenide, $1.0 \mathrm{ng}$ thianthrene and $10 \mathrm{ng}$ triphenylarsine. Reprinted with permission granted by Elsevier Science Publishers BV from "Inter-Elemental Selectivity, Spectra and Computer-Generated Specificity of Some Main Group Elements in the Flame Photometric Detection" by W.A. Aue, X.-Y. Sun, and B. Millier, Journal of Chromatography, Vol. 606, p. 73 (1992).

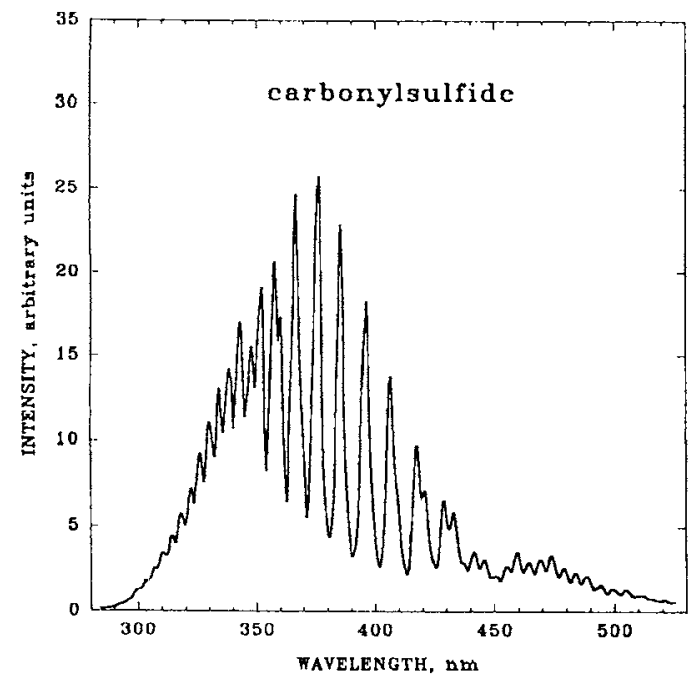

Figure 8

$S_{2}$ luminescence (obtained from continuous introduction of COS) measured with an FPD in the "quadratic mode". Conditions: hydrogen $50 \mathrm{~mL} / \mathrm{min}$, air 40 $\mathrm{mL} / \mathrm{min}$, bandpass ca. $6.7 \mathrm{~nm}$. Reprinted with permission granted by Elsevier Science Publishers BV from "Spectrum, multi-element selectivity and elemental response of a linear sulphur emitter in flame photometry" by W.A. Aue and X.-Y. Sun, Journal of Chromatography, Vol. 633, p. 151 (1993).

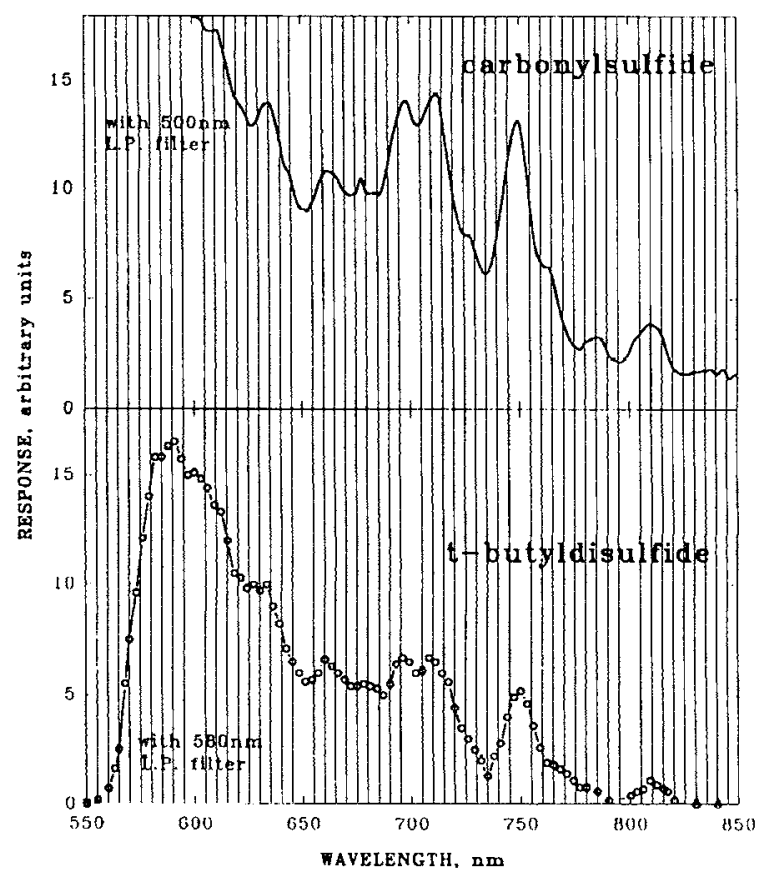

Figure 9

Comparison of sulfur spectra measured with an FPD in the "quadratic" and "linear" mode. Luminescence obtained by continuous introduction of COS (above) and repeated injection of tert-butyldisulfide (below) in the "linear mode". Conditions: hydrogen $500 \mathrm{~mL} / \mathrm{min}$, air $40 \mathrm{~mL} / \mathrm{min}$. Bandpass ca. 6.7 $\mathrm{nm}$ : 500-nm (above) and 580-nm (below) longpass (L.P.) filters are used for order sorting. Reprinted with permission granted by Elsevier Science Publishers BV from "Spectrum, multi-element selectivity and elemental response of a linear sulphur emitter in flame photometry" by W. A. Aue and X.-Y. Sun, Journal of Chromatography, Vol. 633, p. 151 (1993).

remained hidden for so long. In the $600-850 \mathrm{~nm}$ region the sulfur chemiluminescence is a first-order process and varies, if at all, by a factor of less than two in elemental response (sulfur equivalency) among several structurally diverse compounds. A linear response was measured for a band at $\mathrm{ca}$. $750 \mathrm{~nm}$ (where the spectrum has its global maximum) as well as for the wider 600 to $850 \mathrm{~nm}$ range (with a longpass filter). The detection limit measured in the "Inear" sulfur mode is $2 \times 10^{-13} \mathrm{~mol} \mathrm{~S} / \mathrm{s}$ and its linear range spans four orders of magnitude. The detection limit could be improved further by using capillary columns and temperature programmed operation. The authors [59] believes that the emitter of this spectrum is $\mathrm{HSO}\left({ }^{2} \mathrm{~A}^{\prime}-\right.$ ${ }^{2} A$ " electron transition) [60]. The HSO 0,1 band shows up clearly at $749 \mathrm{~nm}$. The 0,0 and 1,1 bands occur at 696 and $711 \mathrm{~nm}$. The 2,0; 1,0 and 0,2 bands at 634,663 and $809 \mathrm{~nm}$ appear to be present as well (Figure 9). Some other advantages of the linear FPD have been emphasized: (i) the response of hydrocarbons is generally negative, thereby providing a quantitative distinction between compounds that contain sulfur and those that contain only carbon and hydrogen; (ii) only a minor dependence of the response of sulfur on the compound structure; (iii) preliminary experiments indicate that the linear sulfur mode suffers significantly less from quenching by co-eluting hydrocarbons than does the quadratic mode. Overall, the new linear mode appears to be superiour over the conventional quadratic one, and it appears competitive with other methodologies of organosulfur detection. On the other hand the authors have also emphasised that the range of compounds tested in this study is limited (only seven) and that the present conclusion should remain open to future re-evaluation.

Driscolland Berger [61] developed an FPD which employs rare-earth glass filters, improving the sensitivity by eliminating angular de- 
pendence, which occurs with interference filters. At the same time, the detector sensitivity is improved by a factor of $2-3$ owing to simultaneous detection of the various $\mathrm{S}_{2}{ }^{*}$ emission lines.

A very interesting and highly promising development in the field of flame photometric detection was published by Cheskis et al. [62] in 1993. Cheskis described a novel gas chromatographic detector based on the flame photometric principle: the Pulsed-Flame Photometer. The pulsed-flame photometric detector (P-FPD) is based on a flame source and a combustible gas flow rate that cannot sustain continuous-flame operation. Thus, the ignited flame propagates back to the combustible gas mixture source and is self-terminated after the combustible gas mixture is burnt. The continuous

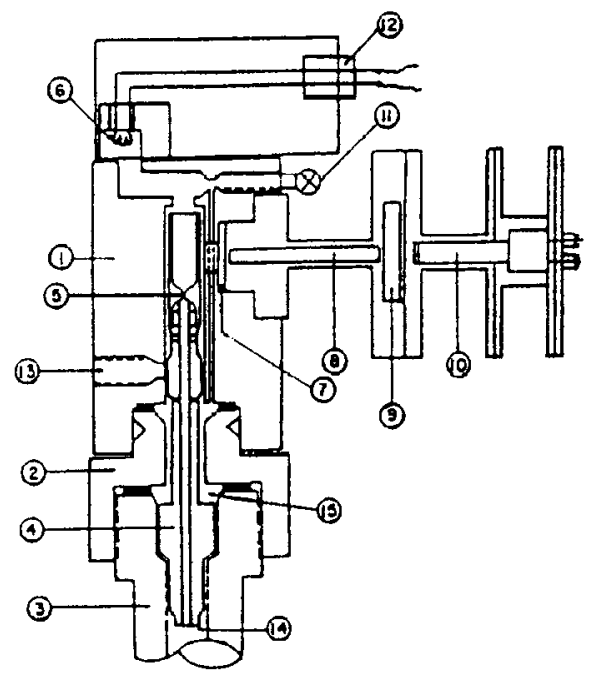

Figure 10

Schematic diagram of the pulsed FPD. The optical detection system is not drawn to scale. (1) main structure, (2) GC adapter, (3) GC-FID mount, (4) combustion cell holder, (5) quartz combustor, (6) igniter, (7) window, (8) quartz rod light guide, (9) color glass filter, (10) photomutiplier, (11) auxiliary screw valve, (12) igniter and heater electrical feedthroughs, (13) external material sampling inlet, (14) hydrogen inlet, (15) air inlet. Reprinted with permission from "Pulsed-Flame Photometer: A Novel Gas Chromatography Detector" by S. Cheskis, E. Atar, and A. Amirav, Analytical Chemistry, Vol. 65, p. 539. Copyright 1993 American Chemical Society.

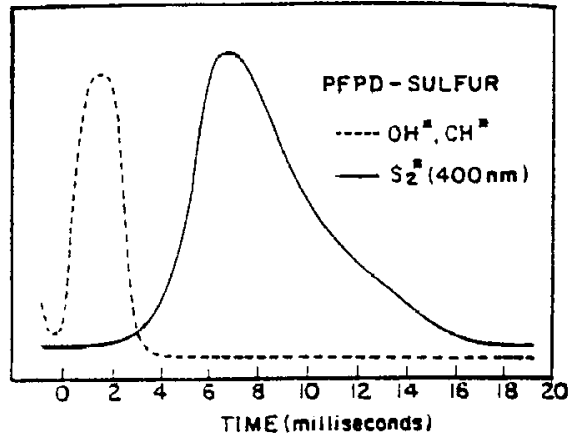

Figure 11

Time dependence of sulfur and carbon emission measured with an pulsedFPD. PFPD emission time dependence of sulfur $\left(S_{2}{ }^{*}\right)$ (solid line) is obtained at $395 \mathrm{~nm}$ through a monochromator and that of $\mathrm{OH}$ is obtained at $312 \mathrm{~nm}$ (dashed trace) which is identical to that of hydrocarbon emission such as $\mathrm{CH}$ or $\mathrm{C}_{2}{ }^{*}$. Detector temperature was $150^{\circ} \mathrm{C}$ and very hydrogen rich flame conditions were used. Tetrahydrothiophene was introduced as the source of sulfur. The combustion cell length was $10 \mathrm{~mm}$. The viewing window is $5 \mathrm{~mm}$ in diameter and is centered on the combustor. Reprinted with permission from "Pulsed-Flame Photometer: A Novel Gas Chromatography Detector" by $\mathbf{S}$. Cheskis, E. Atar, and A. Amirav, Analytical Chemistry, Vol. 65, p. 539. Copyright 1993 American Chemical Society. gas flow creates additional ignitions in a periodic fashion. A schematic diagram of the P-FPD is shown in Figure 10.

The main feature that characterizes the P-FPD is the pulsed-nature of the emitted light. Time domain information is added to the heteroatom specific emission with time dependent emission being observed (e.g. Figure 11). The main advantages of the P-FPD include improved detection sensitivity for $S$ and $P$, much higher selectivity against hydrocarbon molecules, lower gas consumption, reduced emission quenching, additional temporal information, and the ability to detect selectively other heteroatoms such as nitrogen or the simultaneous detection of $\mathrm{S}$ and $\mathrm{C}$. The minimum detection levels achieved are $2 \times 10^{-13} \mathrm{~g} \mathrm{~S} / \mathrm{s}, 1 \times 10^{-14} \mathrm{~g} \mathrm{P} / \mathrm{s}, 5 \times 10^{-12} \mathrm{~g} \mathrm{~N} / \mathrm{s}$, and $6 \times 10^{-11} \mathrm{~g} \mathrm{C} / \mathrm{s}$. The sulfur concentration dependence of the $\mathrm{P}-\mathrm{FPD}$ is quadratic and its response is independent of the structure of the sulfur-containing molecules (linear factor $n=2.00 \pm 0.03$ ). A comparison between the commercial double-flame photometer and the pulsed FPD is shown in Figure 12.

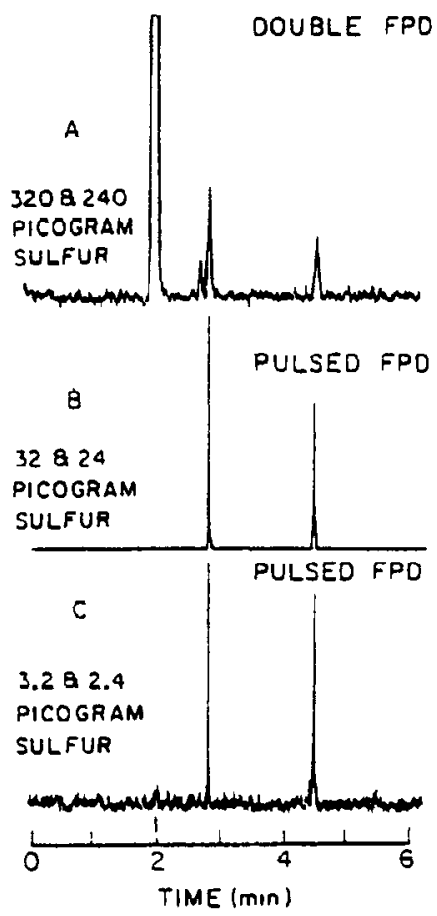

Figure 12

Comparison between the commercial double flame photometer (DFPD) (Varian) and the pulsed FPD (PFPD). Standard Varian FPD test sample was used containing $20 \mathrm{ng} / \mu \mathrm{L}$ each 1-dodecane-thiol, tributyl phosphate, methylparathion and $4000 \mathrm{ng} / \mu \mathrm{L} n$-pentadecane in isooctane. A $30-\mathrm{m}$ capillary $(0.25$ $\mathrm{mm}$ i.d. DB-1) column was used at $220^{\circ} \mathrm{C}$. (A) $2 \mu \mathrm{L}$ were injected with a 20:1 split ratio with the DFPD being used in the sulfur mode. (B) $1 \mu \mathrm{L}$ was injected with a split ratio of 100:1. The PFPD was used in the sulfur mode. (C) $0.10 \mu \mathrm{L}$ was injected with a split ratio of 100:1. Again the PFPD was used in the sulfur mode. The detector response times are $1 \mathrm{~s}$ for the DFPD and $0.3 \mathrm{~s}$ for the PFPD. Reprinted with permission from "Pulsed-Flame Photometer: A Novel Gas Chromatography Detector" by S. Cheskis, E. Atar and A. Amirav, Analytical Chemistry, Vol. 65, p. 539. Copyright 1993 American Chemical Society.

\subsection{Improvements in Sulfur Chemiluminescence Detection}

In contrast to the flame photometric detector which has already been commercially available for over 25 years, the sulfur chemiluminescence detector (SCD) only became available some six years ago. In the SCD sulfur containing components are converted to SO by means of a reducing flame or a furnace-based converter. Currently, two designs which differ in the way the SO converter is set-up are available. In the flame-based system a ceramic sampling 
probe and a vacuum system is used to collect the gases from the flame of an FID. SO is then sensitively detected based on an ozone-induced chemiluminescence reaction to form electronically excited $\mathrm{SO}_{2}{ }^{*}$ which relaxes by emission of light in the wavelength range of $280-420 \mathrm{~nm}$. The SCD can be coupled to the flame housing of a flame ionization detector (FID) and hence is compatible with most existing GC instruments. Apart from the SCD signal of the sulfur components also an FID signal is obtained, although the settings of both hydrogen and air are well outside optimum. Recently, a new version of the SCD became commercially available. In this instrument conversion of the sulfur components to SO no longer takes place in the FID flame. The instrument contains an enclosed flame converter. In the absence of the FID the need for manual adjustment of the position of the ceramic tip in the FID flame is eliminated which greatly simplifies operation. The sensitivity of the new version of the SCD is claimed to be five to 10 times higher [49].

\subsection{Mass Spectrometric Detection of Sulfur Compounds}

The combination of gas chromatography with mass spectrometric detection is an extremely powerful tool in the analysis of unknown samples. Mass spectrometric detection offers a selectivity unsurpassed by any of the other selective detection devices. Whereas selective detectors such as those described above only reveal the presence of a certain hetero-atom, the mass spectrometer gives detailed information on the various structural groups present in a molecule. Among the various ionization modes available, especially electron ionization and chemical ionization have gained widespread acceptance. The combination of these two ionization modes with detection of either positive or negative ions results in four basic operational modes showing substantially different sensitivities towards different types of components.

Headley [63] used a bench-top GC/MS system in the electron ionization mode to detect organosulfur compounds in environmental samples, e.g., industrial effluents, surface waters, sediment and fish samples. The electron-impact ion source was used with the electron energy set up at $70 \mathrm{eV}$. The mass range was $45-450$ amu and the scan rate was $1 \mathrm{~s}^{-1}$. Positive ion detection was employed. The compounds were detected in the approximate concentration range from 0.1 to $2000 \mathrm{ppb}$. Bandy et al. [15] developed an accurate technique for the determination of ppt levels of atmospheric $\mathrm{CS}_{2}$. High accuracy and immunity to analyte losses were achieved by using ${ }^{12} \mathrm{C}^{34} \mathrm{~S}_{2}$ as an internal standard and by performing the analysis by GC/quadrupole MS. High sensitivity was achieved by careful tuning of the GC/MS and preconcentration of the $\mathrm{CS}_{2}$ on a Carbosieve B adsorbent. Data acquisition was carried out in the multiple ion detection mode of the INCOS data system (Finnigan Instruments, Sunnyvale, CA). Mass windows of 75.75 amu to 76.25 amu and 79.75 amu to 80.25 amu were monitored for $0.2 \mathrm{~s}$ each. Parent ions of ${ }^{12} \mathrm{C}^{32} \mathrm{~S}_{2}$ and ${ }^{12} \mathrm{C}^{34} \mathrm{~S}_{2}$, respectively, could be monitored in these windows. Optimization studies showed that an electron energy of $30 \mathrm{eV}$ produced the best compromise between signal and background.

Giuze et al. [64] used GC/quadrupole MS to analyze sulfur compounds in gasoline. Specific detection of sulfur species could be achieved by using the quadrupole analyzer in the chemical ionization mode with ammonia as the reagent gas with detection of negative ions. The authors concluded that the selectivity gained by using the negative ion chemical ionization mode (NICI) was high enough to selectively detect sulfur components on low resolution quadrupole mass spectrometers, even without preliminary separation of the samples.
In low resolution MS, chemical ionization using ammonia as the reactant gas increases the selectivity. In this ionization mode, the mass spectra obtained are fairly simple. The pseudomolecular ion as the base peak is characteristic. Unfortunately, mercaptans have very low molecular weights. It is hence necessary to start mass acquisition below $34 \mathrm{amu}$, the molecular weight of $\mathrm{H}_{2} \mathrm{~S}$. With positive ion detection the reactant gas produces a considerable background noise in the low mass range. On the other hand with negative ion detection, no background noise occurs in the low mass range resulting in an improved sensitivity for sulfur compounds [64] Mass spectra obtained with positive CI are very similar to EI ionization, unlike negative CI which is totally different from it [64]. The high electron affinity and the low background noise level in the low mass range render negative ion-CI the most suitable ionization technique for GC/MS analyses of volatile sulfur compounds.

In high resolution mass spectrometry the principle is to measure only the $\mathrm{CHS}^{+}$fragment which is one of the fragments from $\mathrm{R}-\mathrm{SH}$ compounds. At mass 45, there are at least 7 other species that could interfere with $\mathrm{CHS}^{+}$at low mass resolution. Only $\mathrm{CHS}^{+}$, and ${ }^{13} \mathrm{CC}_{2} \mathrm{H}_{8}$ fragments are issued from the sample. All the other ions are background impurities. $\mathrm{M} / \Delta \mathrm{M}$ is the resolution required to completely resolve other ionic species which have the same nominal mass. At a resolution of $3400, \mathrm{CHS}^{+}$is totally isolated. The resolution of a quadrupole mass analyzer is only $2 \times \mathrm{M}=90$ at mass 45

Recently, selective detection of sulfur-containing compounds by a new GC/MS combination technique, GC/Chemical Reaction Interface MS, was reported [65]. The principle of this new method is based on the creation of a reaction interface by addition of a reactant gas to a low pressure microwave-induced plasma. In this interface complex molecules are converted into small polyatomic neutral species. For a given reactant gas the array of these small molecules reflects the elemental composition of the original analyte. Moini et al. found that $\mathrm{HCl}$ is highly effective as a reactant gas for selective detection of sulfur containing compounds. In a low pressure microwave-induced plasma (temperature of about $4000-6000 \mathrm{~K}$ [65]), the

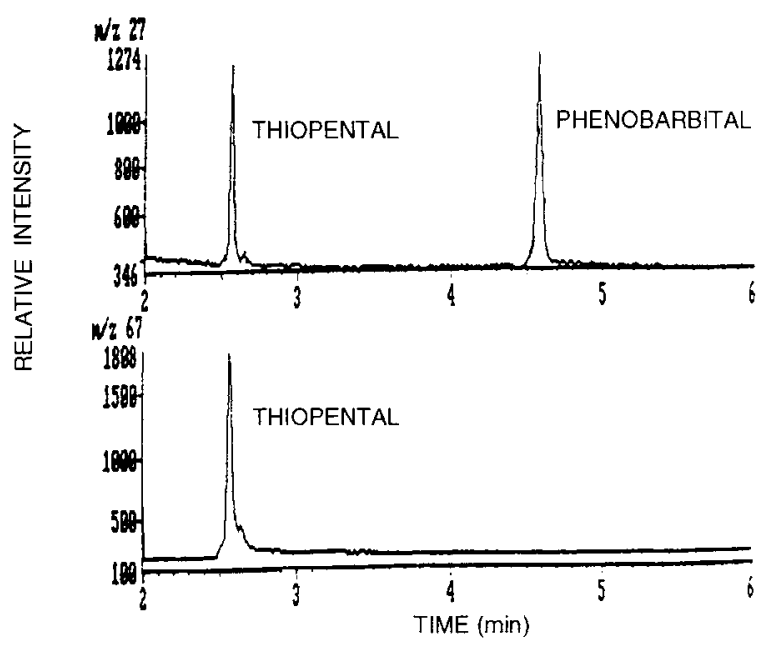

Figure 13

Selective detection of sulfur compounds by GC/Chemical reaction Interface MS. Chromatogram at $\mathrm{m} / \mathbf{2} 67$ using a mixture of thiopental ( $6.6 \mathrm{ng}$ on-column) and phenobarbital (26.4 $\mathrm{ng}$ on-column) is selective sulfur channel. The chromatogram at $\mathrm{m} / \mathrm{z} 27(\mathrm{HCN})$ is a non-selective carbon channel. Reprinted by permission of Elsevier Science, Inc. from "Selective Detection of Sulfur-Containing Compounds by Gas Chromatography/Chemical Reaction Interface Mass Spectrometry" by M. Moini, D. Chace, and F. P. Abramson, Journal of the American Society for Mass Spectrometry, Vol. 2, p. 250-255. Copyright 1991 by the American Society for Mass Spectrometry. 
components eluting from the GC column are completely decomposed. When the decomposition products leave the hot region of the plasma they react rapidly with the reactant gas to produce thermodynamically stable neutral molecules. The mass spectra of selected neutral molecules identify and quantify the elements of interest. In the case of sulfur compounds with $\mathrm{HCl}$ as reactant gas, sulfur predominantly (>95\%) produced $\mathrm{SCl}$ at $\mathrm{m} / z 67$ and 69 and detection at $m / z 67$ was completely selective for sulfur (Figure 13) Detection limits as low as $30 \mathrm{pg}$ of a sulfur-containing compound and a dynamic range of two orders of magnitude were achieved.

The high specificity of the GC/MS technique in sulfur analysis was also proved in a large series of other experiments, particularly in the determination of sulfur containing compounds in gas and oil fractions of local petroleum industry, e.g. the analysis of thiophenes in gas condensates of the Urtabulak field of Uzbekistan [66,67], the study of the composition of sulfur compounds of Lyalmikar and Kokaity petroleums [68], and the analysis of organosulfur compounds of petroleums of the Ural-Volga region [69,70]. Mass spectrometers have also been used in comparative studies of different detection methods [71,72].

\subsection{Other Detection Systems for Sulfur Analysis}

Apart from the FPD, SCD and MS also other sulfur selective detectors have been employed in the determination of sulfur compounds in various matrices [73-77]. The basic principles and applications of these detection systems have recently been reviewed by Wardencki and Zygmund [45]. A comparison of the main characteristics of the different sulfur selective detection systems is presented in Table 2 .

\section{Table 2}

Basic characteristics of various sulfur selective detectors.

\begin{tabular}{|c|c|c|c|}
\hline Detector & $\begin{array}{l}\text { Detection limit } \\
\text { (g S/s) }\end{array}$ & $\begin{array}{l}\text { Selectivity } \\
\text { S/C }\end{array}$ & $\begin{array}{l}\text { Linear } \\
\text { range } \\
\text { dynamic }\end{array}$ \\
\hline \multicolumn{4}{|l|}{ FPD } \\
\hline Single flame & $10^{-11}$ & $10^{4}-10^{6}$ & $3^{\text {a) }}$ \\
\hline Dual flame & $10^{-10}$ & $10^{3}-10^{4}$ & $3^{a)}$ \\
\hline Linear response & $10^{-11}$ & $10^{3}$ & 4 \\
\hline Pulsed FPD & $10^{-13}$ & $>10^{7}$ & $2-3^{a)}$ \\
\hline ECD & $\begin{array}{l}\text { Variable, down } \\
\text { to } 10^{-15}\end{array}$ & Variable & 4 \\
\hline \multicolumn{4}{|l|}{ SCD } \\
\hline Flame-based & $10^{-13}$ & $10^{6}-10^{7}$ & $3-4$ \\
\hline Flame-less & $10^{-14}$ & $10^{6}-10^{7}$ & $4-5$ \\
\hline$A E D$ & $10^{-12}$ & $10^{4}$ & $3-4$ \\
\hline HEICD & $10^{-11}$ & $10^{4}-10^{6}$ & $3-5$ \\
\hline PID & $10^{-12}$ & poor & 6 \\
\hline MS & $10^{-11}$ & specific & $2-5$ \\
\hline
\end{tabular}

a) Linearized output from the quadratic reponse

\section{Calibration}

GC based analytical methods are relative methods of determination which means that they require calibration, i.e. the relationship between detector signal and mass or concentration injected has to be established experimentally. The simplest way to calibrate an analytical instrument is to pass a sample containing the species of interest at a known concentration through the instrument and relate the instrument response to concentration. This simple description of the calibration process ignores the real problems which are generally encountered in the calibration process. These problems can be divided roughly into two areas [78]:

\section{1) Preparation of the standards}

2) Assignment of concentration and uncertainty to the composition of the standard.

In this chapter various methods for the preparation of calibration standards are described. Special attention will be paid to methods for the preparation of calibration mixtures for sulfur analysis. Due to the adsorptive nature of sulfur components extreme care should be taken in both preparation of the standards as well in storage

The most common procedure for calibration in quantitative instrumental analysis is the use of so-called calibration graphs [79]. In the one point calibration graph, one sample of known concentration is analysed in the analytical instrument under the same conditions as those subsequently used for the real samples. Next, a calibration line is constructed by drawing a straight line through the origin and the experimental point. For the two point calibration graph or for multiple linear calibration, the analyst takes a series of samples in which the concentration of the analyte is known. It is essential that the calibration standards cover the entire range of concentrations required in the subsequent analyses. The concentrations of the test samples are normally determined by interpolation and not by extrapolation. Furthermore, it is important to include the value of a "blank" sample in the calibration curve. The blank contains no deliberately added analyte, but does contain the same solvents, reagents, etc. as the other test samples and is subjected to exactly the same sequence of analytical procedures

Non-linear calibration graphs can be used in situations where the relationship between the detector signal and the concentration or mass of compounds of interest is clearly non-linear. Particularly common is the situation where the calibration plot is linear (or approximately so) at low analyte concentrations, but becomes curved at higher analyte levels. In other cases, e.g. classical FPD signal vs concentration plots, it is obviously curved at all concentrations. For a more detailed discussion of the mathematics involved in linear and non-linear calibration the reader is reffered to the excellent textbook written by J. C. Miller and J. N. Miller [79]

\subsection{Methods for Preparing Standard Mixtures in Natural Gas Analy- sis}

For the construction of the calibration graph, standards of accurately known concentrations are needed. A number of methods for the preparation of calibration gases for gas analysis are described by the ISO organisation. These methods can be roughly classified as static or dynamic. Static methods involve preparing and storing the mixture in a closed vessel, for example a cylinder, flask or plastic bag. The sample volume is thus limited to that of the container. Cylinders must be used to store mixtures at high pressures. Static systems are preferred when comparatively small volumes of mixtures are required at moderately high concentration levels, but losses of components by adsorption on the vessel walls may occur. Dynamic systems generate a continuous flow of mixture and can produce large volumes, with lower surface losses, owing to an equilibrium between the walls and the flowing gas stream.

Figure 14 shows a schematic diagram of the preparation methods of calibration gas mixtures used in natural gas analysis. If the concentration of the component in a calibration gas mixture is directly related to the measurement of basic standard units (mass, 


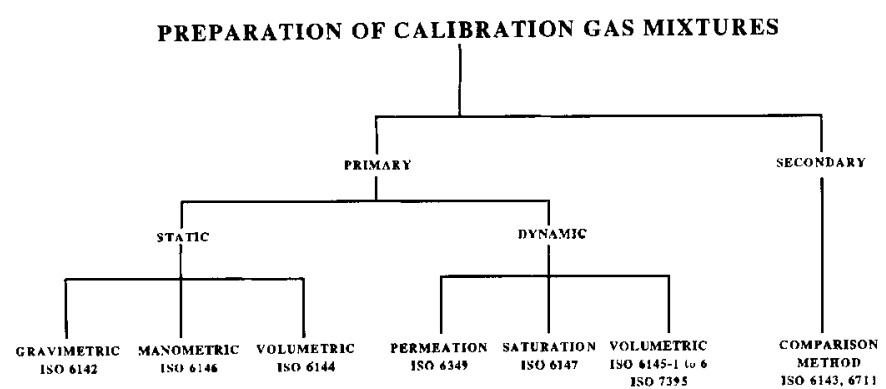

Figure 14

Schematic representation of the preparation methods for calibration gas mixtures used in the natural gas industry. For a more detailed discussion of the principles of the various preparation methods the reader is referred to the isO standards given below.

time, length, etc.) than this mixture is a so-called primary calibration gas mixture.

If a primary calibration gas mixture is used for establishing the composition of another calibration gas mixture this last mixture is a so-called secondary calibration gas mixture.

The best claimed accuracies of the standardized methods referredto in Figure 14 are summarized in Table 3 [80]

Table 3

Best claimed accuracies of standardized methods for the preparation of calibration gas mixtures [80].

\begin{tabular}{llc}
\hline Method & Number of ISO & Accuracy (\%) \\
\hline Gravimetric & ISO 6142 & $<1$ \\
Manometric & ISO 6146 & 1 \\
Permeation & ISO 6349 & 2 \\
Saturation & ISO 6147 & 3 \\
Dynamic volumetric & ISO 6145-1 to 6 & \\
& ISO 7395 & $2-5$ \\
Static volumetric & ISO 6144 & $3-7$ \\
Comparison & ISO 6143, 6711 & - \\
\hline
\end{tabular}

One of the requirements of the analytical procedures in which the calibration gas mixtures are applied, is that the composition of the natural gas to be analyzed and that of the calibration gas mixture should have a close resemblance. In practice this means that a gravimetric preparation method should be used to prepare calibration gas mixtures. With the gravimetric method it is possible to prepare compositions very close to the desired composition. The precision of this gravimetric preparation method has been evaluated [81]. The following errors have to be taken into account when calculating the final composition of a calibration gas mixture prepared using this method:

1) Systematic errors, which are inherent to the procedures used. The use of different lots of reagent gases, different weights of gases, different operators and even different balances helps to reduce systematic errors arising in the process. A systematic error in the procedure however, can only be recognized by comparison of the standards to standards prepared by a totally different method or by analysis using an absolute method. The difference between the two methods of preparation, or the method of preparation and the method of analysis should be less than the statistically predictable difference based on all of the observed random errors.

2) Impurities in the pure gases: This error can be accounted for by carefully analyzing the pure gases and taking into account these impurities when calculating the final composition of the calibration gas mixtures
3) Weighing errors: Koning and van Rossum found that the uncertainty in the concentration of methane of a gravimetrically prepared seven component calibration gas mixture caused by weighing errors can be as low as $1.6 \times 10^{-4} \%$ [81]. For this particular calibration gas mixture the total weighing error is $2.0 \times 10^{-4} \%$.

4) Inaccuracy in the relative molecular masses. Large variation can occur in nature in the ${ }^{13} \mathrm{C} /{ }^{12} \mathrm{C}$ ratio of methane. This causes the molecular weight of methane to vary by $7.5 \times 10^{-3} \%$ depending on the origin of the methane. For the seven-component calibration gas mixture referred to above the total error caused by the uncertainty in the relative molecular masses is $8.2 \times 10^{-3} \%$. Surprisingly, the inaccuracy in the relative molecular masses seems to be the largest error in the gravimetric preparation method of multi-component calibration gas mixtures

Finally the conclusion can be drawn that in a two liter high pressure gas cylinder, multi-component calibration gas mixtures can be prepared by a gravimetric method with a total error smaller than $0.01 \mathrm{~mol} \%$ (total uncertainty of less than $0.5 \%$ relative [78]). In this conclusion the systematic errors of the gravimetric preparation method have not been taken into account. In practice this certainly means that the total error will be larger depending on how correctly the preparation procedures will be followed

\subsection{Calibration Mixtures for Sulfur Components}

In general, volatile sulfur compounds are very active, highly toxic and odorous. Furthermore, the analysis of sulfur components is only of importance for a limited number of companies. For these reasons calibration mixtures of sulfur compounds have never been "commercialized", this in contrast to the hydrocarbon calibration gas mixtures described above. There are several methods for the preparation of sulfur calibration gas mixtures for use in laboratory experiments

The choice of the materials coming into contact with the sulfur species is very important due to the reactivity of sulfur gases. Stability tests were conducted by Bishop et al. [82] on natural gas with high concentrations of sulfur components stored in teflon, rubber, polyethylene, polypropylene and stainless steel containers. The following results were achieved. Mercaptans stored in all systems except teflon and stainless steel suffered severe dissipation within two hours. Mercaptans stored in teflon containers experienced less than $20 \%$ dissipation in 14 to 18 hours. In steel cylinders the mercaptans were found to dissipate substantially within the first day, with a very strong dissipation probably within the first few hours. Based on these results, the long-term storage of sulfur containing gases is apparently not feasible [82].

The single rigid chamber is a simple, easy to use mixing device. A known amount of the compound of interest is introduced into a single rigid chamber of known dimensions. A magnetic stirrer or a similar device is used for homogeneous mixing. The concentration of the standard mixture produced is given by equation 1 .

$C=C_{0} \exp \left(-\frac{V_{\mathrm{w}}}{V}\right)$

$C$ instantaneous concentration

$C_{0}$ : initial concentration

$V$ : container volume

$V_{\text {w: }}$ volume of sample withdrawn

Tangerman et al. [12] prepared gaseous standards for daily calibration in 15-mL glass sample vials. Ethylmercaptan, DMS, and DMDS were injected into these vials as liquids ( $10 \mu \mathrm{L}$ of each), while $\mathrm{H}_{2} \mathrm{~S}$ 


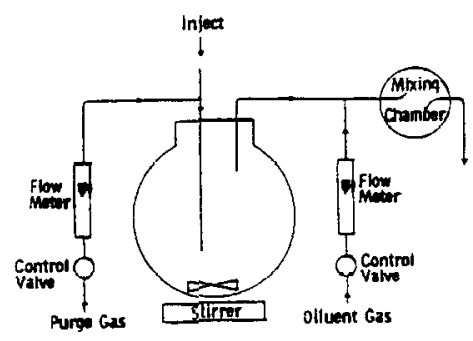

A

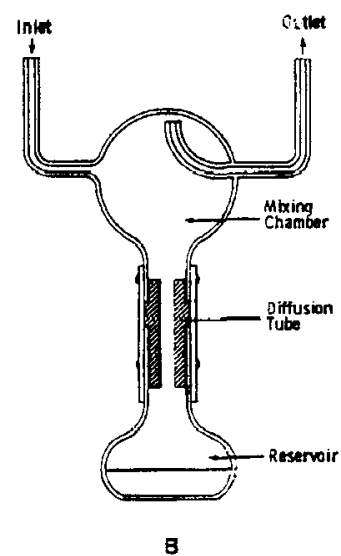

Figure 15

Apparatus for preparing standard mixtures of organic vapors. A: Exponential dilution flask; B: Diffusion tube system. Reprinted with permission granted by Elsevier Science Publishers BV from "Contemporary Practice of Chromatography" by C.F. Poole and S.A. Schuette, Elsevier, Amsterdam, The Netherlands, 1984, p. 485.

and methylmercaptan were added in the gaseous state $(2.5 \mu \mathrm{L}$ - at $20^{\circ} \mathrm{C}$ ). In further experiments [13] Tangerman used this procedure for the preparation of sulfur gas standard samples. Unfortunately, no concrete statistical evaluations, e.g. accuracy of the method were reported.

The exponential dilution flask, shown in Figure 15a [83], is a hybrid static/dynamic system. A known amount of a pure component or a standard mixture is introduced into the vessel, which is stirred for efficient mixing. The vessel is continuously flushed with a steady stream of pure gas causing the concentration of the vapor to decrease with time. This simple, reliable device is commercially available and has been widely used. It produces an outlet concentration described by equation 2 .

$C=C_{0} \exp \left(-\frac{Q t}{V}\right)$

Q. volumetric gas flow rate

t. time after sample introduction

The exponential dilution flask suffers from a number of principal problems such as losses by surface adsorption, mechanical wear of the mixing device, and the difficulty of accurately measuring the initial sample concentration. However, it is capable of providing adequate accuracy and precision for most of the analytical applications involving readily volatilized substances. Very low gas phase concentrations can be prepared by mixing the output from the flask with diluent gas.

De Souza [23] diluted standard high purity gases in both glass bottles or exponential flasks coated with Siliclad in order to passivate the flask towards the reactive sulfur gases. Nitrogen was used as the dilution gas. Standard mixtures of sulfur compounds in $\mathrm{CO}_{2}$ at $\mathrm{ppb}$ levels were prepared by Pick [25] using the exponential dilution apparatus. This apparatus consists of a 1.2 I glass flask with a large Teflon-coated magnetic stirrer bar which was rotated at maximum speed. Initial dilutions of the sulfur compounds were made up in glass vessels fitted with an injection septum and a magnetic stirrer in order to give concentrations in the range of 250 to $1000 \mathrm{ppm}$. Diluted samples were then injected into the $\mathrm{CO}_{2}$ stream flowing into the exponential dilution flask to give concentrations between 50 and $1000 \mathrm{ppm}$. By using various initial concentrations the efficiency of the mixing process was checked and found to be satisfactory. However, the $\mathrm{CO}_{2}$ flow rate could not be meas- ured to an accuracy greater than $\pm 1 \mathrm{~mL} / \mathrm{min}$; therefore, in order to keep the error arising from flow measurements below $\mathrm{ca} . \pm 3 \%$ the contents of the exponential dilution flask were never diluted by more than a factor of 20 .

Diffusion systems such as the one described in Figure 15b [83], are useful and simple devices for preparing mixtures of volatiles and moderately volatile vapors in a gas stream. The method is based on the constant diffusion of a vapor through a tube of accurately known dimensions, producing a gas phase concentration described by equation (3) [83].

$S=\frac{D M P A}{R T L} \ln \left(\frac{P}{P-p}\right)$

$S$. diffusion rate of vapor out of tube

$D$ : diffusion coefficient

$M$ : molecular weight

$P$. pressure in the diffusion cell

A: cross-sectional area of the diffusion tube

$R$ : gas constant

T. temperature

$L$ : length of the diffusion tube

$p$ : partial pressure of the diffusing vapor at the outlet of the diffusion tube

Within limits, broad concentration ranges can be prepared by varying the tube dimensions and/or the flow rate of the diluent gas.

Permeation tube devices are now very popular for generating standard vapor concentrations. The permeation tube contains a volatile liquid sealed in an inert permeable membrane, usually Teflon or a fluorinated copolymer of ethylene and propylene, through which the test compound diffuses at a fixed rate. The driving force behind the process is the difference in partial pressures between the inner and outer walls of the tubes. This depends on the dissolution of the vapor in the membrane, the rate of diffusion through the membrane wall, and the rate at which the vapor is removed from the outer surface of the membrane. The mass permeation rate per unit tube length can be expressed by equation (4) [83], assuming that the membrane is in contact with the gaseous phase only.

$$
G=\frac{730 P M}{\log \left(\frac{d_{2}}{d_{1}}\right)} \times P_{1}
$$

$G$ : mass permeation rate in $\mu \mathrm{g} / \mathrm{min}$ per $\mathrm{cm}$ of tube length

$P$. permeation constant for the vapor through the membrane in $\mathrm{cm}^{3}$ $M$ : molecular weight of the vapor

$P_{1}$ : gas pressure inside the tube, $\mathrm{mm} \mathrm{Hg}$

$d_{2}$ : outside diameter of the tube

$d_{1}$ : inside diameter of the tube

For samples with a low vapor pressure at room temperature, elevated temperatures are used to raise the permeation rates and to yield desirable concentration values. Gases or vapors with a high membrane permeability require devices other than the standard single-walled tubes, e.g. multiple-walled tubes, microbottles, or permeation wafer devices to yield reasonable lifetimes. Commercially available permeation tubes have lifetimes of several months and provide a simple and inexpensive method of calibration for laboratories interested in determining only a few substances, or for those who need to perform measurements infrequently.

For the analysis of sulfur gases by gas chromatography, permeation devices offer an economical alternative to compressed gas standards. Moreover, the use of these devices offers a safety advantage 
in the handling of toxic sulfur gases while minimizing the chemical reactivity inherent to sulfide and mercaptan compounds [84]. Permeation devices are commercially available through a number of manufacturers and cover the concentration range of $\mathrm{ppb}$ to percent levels.

An international standardized method for the preparation of calibration gas mixtures by the permeation method is available: ISO 6349 - Gas Analysis - Preparation of calibration gas mixtures - Permeation method. The concentration $C$ of the calibration gas mixture so prepared is a function of the diffusion rate of the tube and the flow rate of the complementary gas. It is given by the formula

$C=\frac{q_{m}}{q_{V}}$

$q_{m}$ : permeation rate in $\mu \mathrm{g} / \mathrm{min}$

qV. sweeping flow rate in $\mathrm{m}^{3} / \mathrm{min}$

Some examples of permeation tubes and permeation apparatus made in different laboratories are given in Figures 16 and 17. The use of a thermostatic device is essential to control the temperature of the bath to within $0.1^{\circ} \mathrm{C}$ because the tube diffusion rate may double at an increase in temperature of approximately $7^{\circ} \mathrm{C}$. The accuracy of the concentration obtained depends on the knowledge of two parameters: the diffusion rate of the permeation tube and the flow rate of the complementary gas. In general it is within $5 \%$.

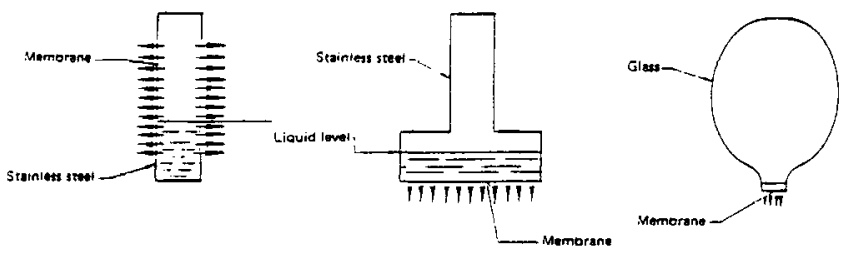

Cytimerical tub
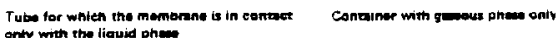

Figure 16

Examples of permeation tubes.

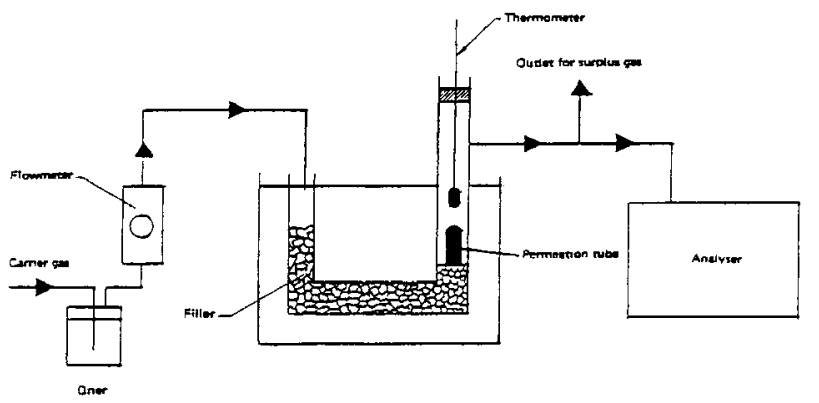

Figure 17

Example of a permeation system for the preparation of calibration standards.

The permeation rates are usually calibrated gravimetrically $[85,86]$. Primary calibration of a liquid-filled tube can be obtained by collecting weight data (losses) over a period of days, weeks, or months. Between weighing, the tube should be stored in a chamber maintained at a constant temperature $\left( \pm 0.1^{\circ} \mathrm{C}\right)$ and at low humidity (silica gel desiccant).
Common dilution gases are air $[4,10,35]$, argon [7], helium [16] and nitrogen $[24,26]$ which of course should be free of sulfur.

De Souza et al. [87] developed a calibration system for measuring the total reduced sulfur and sulfur dioxide concentrations in ambient air. The system is based on the use of permeation tubes coupled with an exponentional dilution flask. Reproducible calibration curves (log-log scale) were obtained for the concentration range of 1 to $100,0.3$ to 5 , and 0.1 to $1 \mathrm{ppb} \mathrm{SO} 2$ with $\pm 5 \%$ relative error for eight determinations. However, only the calibration curve for the 0.3 to 5-ppb range was straight, while that of the 1 to 100 -ppb range showed a slight deviation at the lower end and that for the 0.1 to $1.0-\mathrm{ppb}$ range showed slight curvature throughout. For the calibration of six individual sulfur compounds, straight-line log-log calibration curves from 5 to $100 \mathrm{ng}$ were obtained with slopes of 2.15, $1.87,1.06,2.26,1.71$, and 1.14 for $\mathrm{H}_{2} \mathrm{~S}, \mathrm{COS}, \mathrm{SO}_{2}, \mathrm{CH}_{3} \mathrm{SH}, \mathrm{DMS}$, and DMDS, respectively. The low slope values for $\mathrm{SO}_{2}$ and DMDS could be due to the very active nature of $\mathrm{SO}_{2}$ and the heavy nature of the DMDS; hence partial losses in the packing material of the sample preconcentrator might occur.

The G-Cal tube [84] is a commercially available permeation device which possesses sufficient thermal stability to permit usage without thermostatic control. The G-Cal device exhibits a $1-3 \% / \mathrm{K}$ change in permeation rate near ambient temperatures. To generate multi-component gas standards the permeation tubes could be hooked in series. The analyses of calibration mixtures containing $0.87 \mathrm{ppm}$ of DMS and $1.30 \mathrm{ppm}$ of methyl mercaptan represent a percent deviation of $2 \%$, which is typically within the error limits expected from conventional permeation devices [86].

From the literature study described in this chapter it can be concluded that for the accurate calibration during the analysis of volatile sulfur compounds permeation tubes or diffusion devices are the best choice. However, for the "gross" determination of these components, when the demand posed on the accuracy is not so critical, a simple single rigid chamber is satisfactorily as well. In general, the use of gravimetrically prepared calibration gas mixtures yields a better repetability and accuracy than these devices. For the particular case of sulfur components, however, it appears that this conclusion is no longer valid. The strong adsorptivity of sulfur components give rise to adsorption losses and hence, calibration errors unless special precaution e.g. Teflon passivation of the inner wall are taken. With higher boiling sulfur compounds such as ethylmercaptan and its higher homologes calibration solutions can be made in for example hexane. These mixtures should be stored in a refrigerator.

\section{Conclusion}

The determination of sulfur containing components in natural gas is a typical example of trace analysis in a complex and interfering matrix. Gas chromatography has proven to be an extremely useful technique for this difficult analytical problem. In order to obtain the maximum possible performance, each of the three steps of the analytical procedure, i.e. sample preparation, separation, and detection has to be carefully optimized and fine-tuned to meet the requirements of the other two steps of the procedure. In this respect the choice of the detector plays a key role. Despite tremendous progress in the field of especially flame photometric and sulfur chemiluminescence detection, at present no detector is available that provides the selectivity and sensitivity required to keep pace with the ever more stringent demands currently being imposed on sulfur detection limits and analytical accuracy. Optimized chromatographic separations have to be incorporated in the analytical 
procedure. Due to their high resolving power capillary columns are to be prefered over the classical packed columns. The sensitivity of the analytical system can be improved by preconcentration of the sulfur components on a suitable solid adsorbent prior to transfer of the sample on to the chromatographic column. Polar adsorbents appear highly promising as these materials could provide selective enrichment of the components of interest. For calibration of GCbased analytical techniques for sulfur determination in natural gas, dynamically generated calibration standards appear to be more reliable than statically prepared standards. Adsorption losses which are unavoidable in static calibration, are significantly lower or often even fully absent in dynamic system such as permeation or diffusion devices

\section{References}

[1] A.L.C. Smit and E. Meijer, Proceedings of the Congress of "Gas Quality Specification and Measurement of Physical and Chemical Properties of Natural Gas", Groningen, The Netherlands, 22-25 April 1986, Elsevier, Amsterdam, The Netherlands, 1986, p. 589.

[2] ISO 6326-1 (E): International Standard: "Natural Gas-Determination of Sulfur Compounds" Part 1: "General Introduction", Geneve, Switzerland, 1989.

[3] D.F.S. Natusch, H.B. Klonis, H.D. Axelrod, R.J. Teck, and J.P. Lodge, Jr., Anal Chem. 44 (1972) 2067.

[4] H.D. Axelrod and S.G. Hansen, Anal. Chem. 47 (1975) 2460

[5] P.W. West and G.C. Gaeke, Jr. Anal. Chem 28 (1956) 1816.

[6] R.S. Braman, J.M. Ammons, and J.L. Bricker, Anal. Chem. 50 (1978) 992

[7) R.A. Kagel and S.O. Farwell, Anal. Chem. 58 (1986) 1197.

[8] S.O. Farwell, D.P. Liebowitz, R.A. Kagel, and D.F. Adams, Anal. Chem. 52 (1980) 2370

[9] M.S. Black, R.B. Herbst, and D.R. Hitchcock, Anal. Chem. 50 (1978) 848

(10) P.A. Steudler and W.Kijovski, Anal. Chem. 56 (1984) 1432

[11] A. Przyjazny, J. Chromatogr. 333 (1985) 327.

[12] A. Tangerman, M.T. Meuwese-Arends, and J.H.M. van Tongeren, Clinica Chimica Acta $130(1983) 103$

[13] A. Tangerman, J. Chromatogr. 366 (1986) 205.

[14] J.J. Henatsch and F. Jüttner, J. Chromatogr. 445 (1988) 97.

[15] A.R. Bandy, B.J. Tucker, and P.J. Maroulis, Anal. Chem. 57 (1985) 1310

[16] F. Caron and J.R. Kramer, Anal. Chem. 61 (1989) 114.

(17) S.O. Farwell, S.J. Gluck, W.L. Bamesberger, T.M. Schutte, and D.F. Adams, Anal Chem. 51 (1979) 609.

[18] R.K. Stevens, J.D. Mulik, A.E. O'Keeffe, and K.J. Krost, Anal. Chem. 43 (1971) 827

[19] F. Bruner, B. Ciccioli, and F. Di Natra, Anal. Chem. 47 (1975) 141.

[20] D. Suier and A. Hill, J. Chromatogr. Sci. 20 (1982) 429

121] T.L.C. de Souza, D.C. Lane, and S.P. Bhatia, Anal. Chem. 47 (1975) 543.

[22] C.A. Burgett, The Rapid Determination of $\mathrm{H}_{2} \mathrm{~S}_{1} \mathrm{COS}$, and $\mathrm{SO}_{2}$ by Gas Chromatography. Hewlett-Packard Application Note ANGC5-75, Hewlett-Packard Company, Avondale, Pennsylvania, 1975.

[23] T.L.C. de Souza, J. Chromatogr. Sci. 22 (1984) 470.

[24] C.D. Pearson, J. Chromatogr. Sci. 14 (1974) 154

[25] M.E. Pick, J. Chromatogr. 171 (1979) 305.

[26] B.J. Ehrlich, R.C. Hall, R.J. Anderson, and H.G. Cox, J. Chromatogr. Sci. 19 (1981) 245.

[27] V.B. Stein and R.S. Narang, Anal. Chem. 54 (1982) 991.

[28] J.L. Genna, W.D. MCAninch, and R.A. Reich, J. Chromatogr. 238 (1982) 103.

[29] P. Ronkainen, J. Densiow, and O. Leppänen, J. Chromatogr. Scj. 11 (1973) 384.

(30] K.J. Rygie, G.P. Feulmer, and R.F. Scheideman, J. Chromatogr. Sci. 22 (1984) 514

[31] A.H.H. Tameesh, A.O. Bender, and T.M. Sarkissian, J. Chromatogr. 321 (1985) 59

[32] P.A. Gibbons, Chromatographia 19 (1984) 254.

[33] L. Blomberg, J. Chromatogr. 125 (1976) 389.

[34] C.J. Barinaga and S.O. Farwell, J. High Resolut. Chromatagr. \& Chromatogr Commun 9 (1986) 388.
[35] C.J. Barinaga and S.O. Farwell, J. High Resolut. Chromatogr \& Chromatogr. Commun 10 (1987) 538.

[36] S. Jacobsson and O. Falk, J. Chromatogr. 479 (1989) 194

[37] K.K. Gaines, W.H. Chatham, and S.O Farwell, J. High Resolut. Chromatogr. 11 (1990) 585

[38] F. Russo and F. Maghini, Proceedings of the Congress of "Gas Quality - Specification and Measurement of Physical and Chemical Properties of Natural Gas", Groningen, The Netherlands, 22-25 April 1986, Elsevier, Amsterdam, The Netheriands, 1986, p. 633

[39] S.E.A. Monks, Proceedings of the Congress of "Gas Quality-Specification and Measurement of Physical and Chemical Properties of Natural Gas", Groningen, The Netherlands, 22-25 April 1986, Elsevier, Amsterdam. The Netherlands, 1986, p. 641 .

[40] H. Obbens and L. Huber, Proceedings of the Congress of "Gas Quality -Specification and Measurement of Physical and Chemical Properties of Natural Gas", Groningen, The Netherlands, $22-25$ April 1986, Elsevier, Amsterdam, The Netherlands, 1986, p. 649

[41] D. Jentzsch and E. Otte, "Methoden der Analyse in der Chemie" Band 14: "Detektoren in der Gas-chromatographie", Akademische Verlagsgesellschaft, Frankfurt am Main, Germany, 1970

[42] J. Sevcik, J. Chromatogr. Lib., Vol. 4-Detectors in Gas Chromatography, Elsevier Pub., Amsterdam, The Netherlands, 1976

[43] M. Dressler, J. Chromatogr. Lib., Vol. 36-Selective Gas Chromatographic Detectors, Eisevier Pub. Amsterdam, The Netherlands, 1986.

[44] H.V. Drushel, J. Chromatogr. Sci. 21 (1983) 375.

[45] W. Wardencki and B. Zygmund, Anal. Chim. Acta. 255 (1991) 1.

[46] S.S. Brody and J.E. Chaney, J. Gas Chromatogr. 4 (1966) 42.

147] S. O. Farwell and C.J. Baninaga, J. Chromatogr. Sci. 24 (1986) 483

148] P.L. Patterson, R.L. Howe, and A. Abu-Shumays, Anal. Chem. 50 (1978) 339.

[49] M. Dyson, Anal. Proceed. 30 (1993) 79.

[50] A.R. Baig, C.J. Cowper, and P.A. Gibbons, Chromatographia 16 (1982) 297.

[51] J. Efer, T. Maurer, and W. Engewald, Chromatographia 29 (1990) 115

[52] G.H. Liu and P.R. Fu, Chromatographia 27 (1989) 159

[53] J. Zehner and R. Simonaitis, J. Chromatogr. Sci. 12 (1976) 348

[54) W.A. Aue and C.G. Flinn, J. Chromatogr $158(1978) 161$

[55] T. Cardwell and P. Marriot, J. Chromatogr. Sci. 20 (1982) 3017.

[56] J. Sevcik and N. Phuong Thao, Chromatographia 8 (1975) 559

[57] W.A. Aue, X. Y. Sun, and B. Millier, J. Chromatogr. 606 (1992) 73.

[58) W.A. Aue and X.-Y. Sun, J. Chromatogr. 633 (1993) 151

[59] W.A. Aue and X.-Y. Sun, J. Chromatogr. 641 (1993) 291

[60] U. Schurath, M. Weber, and K.H. Becker, J. Chem. Phys. 67 (1977) 110; p. 112. Fig. $2 \mathrm{~B}$

[61] J.N. Driscoll and A.W. Berger, J. Chromatogr. 468 (1989) 303

[62] S. Cheskis, E. Atar, and A. Amirav, Anal. Chem. 65 (1993) 539

[63] J.V. Headley, Biomed. Environ. Mass Spectrom. 14 (1987) 275

[64] J. Guieze, G. Devant, and D. Loyaux, Int. J. Mass Spectrom. Ion Phys. 46 (1983) 313

(65) M. Moini, D. Chace, and F.P. Abramson, J. Am. Soc. Mass Spectrom. 2 (1991) 250

[66] N.V. Agadzhanova, N.K. Lyapina, R.B. Alieva, V.S. Shmakov, and M.A. Parfenova, Neftechimiya, 26 (1986) 132

[67] N.V. Agadzhanova, N.K. Lyapina, R.B. Alleva, V.S. Shmakov, and M.A. Parfenova, Neftechimiya 23 (1983) 424.

[68] Kh. Khaitbaev, E.S. Brodskii, and S.L. Gusinskaya, Dokl. Akad. Nauk Uzb. SSR, 31 (1974) 26 .

[69| R.D. Obolentsev, T. I. Alliueva, G.V. Galeeva, R.P. Kruglyakova, S.S. Krivolapov, and I.M. Salimareeva, Khim. Seraorg. Soedin., Soderzh. Neftyakh Nefteprod. 9 (1972) 364.

[70] R.D. Obolentsev, S.S. Krivolapov, T.I. Allihueva, G.V. Galeeva, V.S. Kaneva, R.P. Kaneva, and N.N. Lyushina, Khim. Serraorg. Seodin. Soderzh. Neftyakh Nefteprod. 8 (1968) 341

[71] Z. Schultheisz, S. Iglewski, M. Kantor, and E. Kerenyi, Magy. Asvanyolaj Foldgaz Kiserl. Intez. Kozlem. 10 (1969) 31. 
[72] I. Schultheisz, M. Kantor, K. Belafi, P. Szepesvary, and E. Kerenyi, Chromatographic and Spectrometric Study of Sulphur Compounds of Cracked Gasolines, paper pres. at Con. Chem. Chem. Process. Petrol. Natur. Gas, Budapest, 1965, p 605.

[73] J.E. Johnson and J.E. Lovelock, Anal. Chem. 60 (1988) 812.

[74] S.E. Eckert-Tilotta, S.B. Hawthome, and D.J. Miller, J. Chromatogr. 591 (1992) 313.

[75] R.C. Mitchner, S. Nacson, and J. Wallace, A portable GC analyzer for on-site analysis of natural gas odorant levels, Paper pres. at IGT Gas Quality Symp. (June 12-13.1989), Chicago, IL, USA

[76] R.G. Schiller and R.B. Bronsky, J. Chromatogr. Sci. 15 (1977) 541

[77] F. Lindquist, J. High Resolut. Chromatogr. 12 (1989) 628.

[78] E.E. Hughes, Proceedings of the Congress of "Gas Quality-Specification and Measurement of Physical and Chemical Properties of Natural Gas", Groningen, The Netherlands, 22-25 April 1986, Elsevier, Amsterdam, The Netherlands, 1986, p. 675.

[79] J.C. Miller and J.N. Miller, Statistics for the Anal. Chem. Ellis Horwood Ltd., 3rd Ed., West Sussex, England, 1993

[80] Internal publication: Lab. Info. Bulletin No. 37, NV Nederlandse Gasunie, Groningen, the Netherlands.
[81] M. Koning and G.J. van Rossum, Proceedings of the Congress of "Gas Quality Specification and Measurement of Physical and Chemical Properties of Natural Gas", Groningen, The Netherlands, 22-25 April 1986, Elsevier, Amsterdam, The Netherlands, 1986, p. 683.

[82] H.K. Bishopand J.R. Bricarello, Odorant Identification and Measurement in Natural Gas by Gas Chromatography, AGA paper pres. at Distrib/Trans Conference, Boston, (1985) 601-605

[83] C.F. Poole and S.A. Schuette, Contemporary Practice of Chromatography, Elsevier, Amsterdam, The Netherlands, p. 485, 1984

[84] D.G. Flowers, Ind. Eng. Chem. Res. 29 (1990) 1565.

[85] A.E. O'Keeffe and G.C. Ortman, Anal. Chem. 38 (1966) 760.

[86] F.P. Scaringelli, A.E. O'Keeffe, E. Rosenberg, and J.P. Bell, Anal. Chem. 42 (1970) 871.

(87) T.L.C. de Souza and S.P. Bhatia, Anal. Chem 48 (1976) 2234

Ms received: January 27, 1994 Accepted: May 19, 1994 